\title{
FINGERING STRATEGIES IN THE PRELUDE OF J.S. BACH'S \\ SIXTH SUITE FOR SOLO CELLO
}

ALEXANDRA CLAIRE PARTRIDGE

A dissertation submitted to Massey University and Victoria University of Wellington in partial fulfilment of the degree Masters of Musical Arts in Classical Performance

New Zealand School of Music 


\section{ABSTRACT}

The introduction of this exegesis presents a brief history of Bach's cello suites, explores the relevance and reliability of the manuscript sources and discusses the intended five-stringed instrument for Suite No. 6. Part One compares and contrasts the fingering patterns within selected extracts from eleven different editions of the Prelude. It examines the varying interpretations and takes into account the fingering choices that have been adopted in the publications. Part Two of this exegesis comprises this author's version of the Prelude. This incorporates the technically and musically convincing fingering patterns found from the research in prior parts of this study, as well as using the author's own knowledge of cello pedagogy. The ultimate purpose of this research is to provide a comprehensive and informed version in which challenges of playing this movement are largely minimised. 


\section{ACKNOWLEDGEMENTS}

First and foremost, my gratitude goes to my family. If it weren't for their love, support and dedication to my musical growth right from day one, my passion would never have been ignited. A huge thank you goes to my past and present teachers, particularly to David Chickering who first delighted me with the Bach Suites, and to Inbal Megiddo for her encouragement and mentorship. Lastly, I would like to express my appreciation to my supervisor Professor Donald Maurice, because his wisdom, guidance and patience helped me through each stage of this exegesis. 


\section{TABLE OF CONTENTS}

INTRODUCTION 1

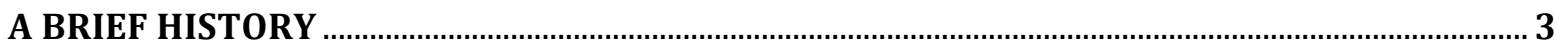

$\begin{array}{ll}\text { PART ONE } & 6\end{array}$

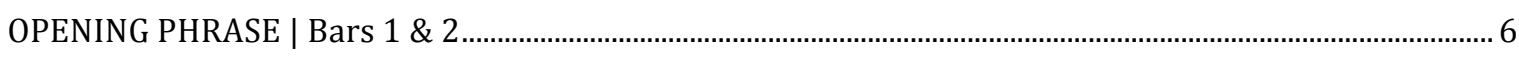

SUPERTONIC MODULATION | Bars 23 - 32 ………………….......................................................................... 12

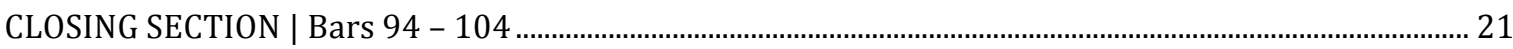

$\begin{array}{ll}\text { PART TWO } & 30\end{array}$

AUTHOR'S NOTES

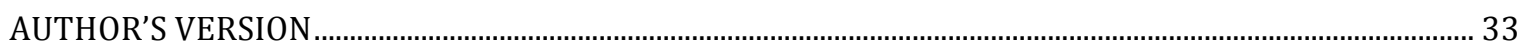



APPENDIX

$\begin{array}{ll}\text { BIBLIOGRAPHY } & 41\end{array}$

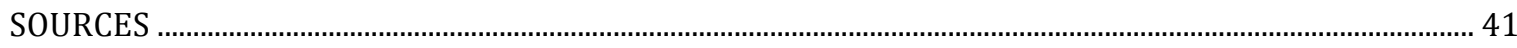

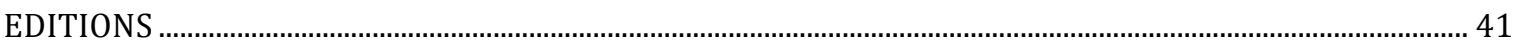

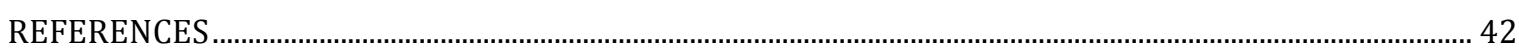

OTHER MATERIAL NOT REFERENCED ………………………................................................................................... 43 


\section{INTRODUCTION}

"Every musician and music-lover, and in particular every string player, seizes upon Bach's Solo Sonatas and Suites for Violin and for Violoncello with admiration and delight, finding in them magnitude and depth, richness and concentration, artistry and craftsmanship, most closely united in unique and exemplary manner."

- August Wenzinger ${ }^{*}$

Currently, there are over 100 editions of J.S. Bach's Six Suites for Violoncello Solo (BWV 1007-1012). The editors of these publications have relied on four secondary manuscript sources and the first edition, from the early $19^{\text {th }}$ century, as their primary reference points, there being no surviving original autograph. As a result, the editions vary widely in matters of style, phrasing, fingering patterns and in some cases, pitch differences. Having no autograph furthermore creates uncertainty surrounding the original instrument intended for the sixth and final suite. The sources indicate that the sixth suite should be executed from a five-stringed instrument. However, because there is no original documentation specifying what this instrument actually is, many question whether it should be played on a cello at all. The lack of a fifth string on today's standard cello creates problematic variations between modern editions specifically with suggested fingering performance marks, and thus, these differences will be the central focus of this exegesis.

The following eleven editions of the Suites have been chosen for close examination due to their diversity in performance marks.

1. Hugo BECKER, C. F. Peters, 1911.

2. Friedrich DOTZAUR, Breitkopf \& Härtel, 1826.

3. Jacqueline du PRÉ, Edition Wilhelm Hansen, 1981.

4. Pierre FOURNIER, International Music Company, 1972.

5. Frits GAILLARD, G. Schirmer, 1939.

6. Friedrich GRÜTZMACHER, C. F. Peters, 1865.

7. Tim HUGH, Kevin Mayhew Ltd., 2005.

8. Julius KLENGEL, Breitkopf \& Härtel, 1900.

9. M R and L ROSANOFF, ECS Publishing: Galaxy Music Corporation, 1963.

10. János STARKER, Peer International Corporation, 1971.

11. August WENZINGER, Bärenreiter-Verlag, 1950.

${ }^{*}$ August Wenzinger, Six Suites for Violoncello Solo BWV 1007-1012 by J.S. Bach: Preface (Basel: Bärenreiter-Verlag, 1950 ), p.2. 
The comparative study of these selected published editions specifically looks into the fingering patterns that editors and performers have chosen to include within several passages of the Prelude. It examines the varying interpretations and takes into account the fingering choices that have been adopted. The fingerings offered by these editors are included within the score to help the player overcome many string-crossing difficulties that are largely created from the lack of a fifth string. In some cases, the fingerings are used to help create an aural variance between the voices in the score.

Two articles and one book, based on the principles of string fingering, were consulted prior to this analysis in order to understand why editors have included particular cello finger markings in their editions. Benjamin Whitcomb has identified and compiled a short list of common and important criteria when choosing fingerings. ${ }^{1}$ An Organised Method of String Playing by János Starker is also referred to for the author's detailed instruction on cello technique with specific focus on hand placement. Donald Maurice's article on the exploration of string colour promotes fingering choices to demonstrate voicing lines by utilising the distinctive qualities of the four strings. ${ }^{2}$

\footnotetext{
${ }^{1}$ Benjamin Whitcomb, 'Strings 101: Music \& Musicians - World of Possibilities: Learn to Devise the Best Cello Fingerings.' Accessed August 30, 2013. http://search.proquest.com.helicon.vuw.ac.nz/docview/1409812?accountid=14782. [See Appendix].

2 Donald Maurice, 'The Art of Vocal Fingerings in String Playing.' American String Teacher 56, no. 3 (August 2006), pp. 27-31.
} 


\section{A BRIEF HISTORY}

The history of the Six Suites for Solo Cello (BWV 1007 - 1012) by Johann Sebastian Bach, hereafter referred to as the "Suites", has been thoroughly scrutinised by musicologists, editors and performers. Given the nature of the uncertainty pertaining to the creation of these Suites, many hypotheses have made their way into music literature in regards to when, and for what reason the composer wrote the set of works for solo cello.

The Suites are thought to have been written whilst Bach was residing in Cöthen and employed as the Kapellmeister to Prince Leopold. During this six-year residency between 1717 and 1723, Bach was able to focus on writing secular works, a dramatic change from his previous position in Weimar where only church music was celebrated. As court composer to the prince, Bach was able to experiment with individual instruments and much emphasis was placed on chamber music. ${ }^{3}$ The court orchestra consisted mainly of proficient string and wind players. Since Prince Leopold was a music enthusiast and a competent player of the violin himself, he saw the importance of having a musical culture. After the Hopfkapelle orchestra in Berlin was disbanded by Friedrich Wilhelm I of Prussia, the Prince of Cöthen promptly secured them to his court. Bach was therefore able to have at his disposal some of the best musicians in the country. Such prominent musicians at the court included Christian Ferdinand Abel, a viol player and Christian Bernhard Lienicke, a cellist. ${ }^{4}$ It is not clear whom Bach had in mind when composing these Suites, if anyone at all. However, it does seem likely that either of these players may have been candidates.

Although exact dates of completion are not known for the Suites, Werner Breig writes that this particular set of works for the cello were supposed to complement Bach's Six Partitas and Sonatas for Solo Violin (BWV 1001 - 1006), which have a surviving autograph from 1720. Breig comments that the autograph fair copy of the sonatas and partitas includes the words Libro Primo (Book One) below the main title and this likely alludes to the fact that the Suites would make up Secondo Libro (Book Two) of the series. ${ }^{5}$ Likewise, Hans Eppstein states that the sets were conceived as a pair of compositions. He explains that this idea is justified with Heinrich Ludwig Schwanberg's description added to Anna Magdalena Bach's manuscript copy of the violin works. ${ }^{6}$ The description reads: "Pars 1. Violino Solo |

\footnotetext{
3 Rhiannon Thomas, Johann Sebastian Bach's Unaccompanied Cello Suites (BWV 1007 - 1012) Sources, Editions and Interpretations (Wellington: Victoria University, 1996), p. 1.

${ }^{4}$ Peter Williams, J.S Bach: A Life in Music (Cambridge: Cambridge University Press, 2007), p. 127.

5 Werner Breig, 'Solo Works', in The Cambridge Companion to Bach, ed. by John Butt (Cambridge: Cambridge University Press, 1997), pp. 126-127.

${ }^{6}$ Hans Eppstein, Johann Sebastian Bach Neue Ausgabe sämtlicher Werke, Series VI, Band 2 (Kassel: Bärenreiter, Kritische Bericht, 1990), p. 18.
} 
Senza Basso | composée | par Sr. Jean Seb: Bach" and "Pars 2. | Violoncello Solo. | Senza Basso. | composée | par| Sr. J. S. Bach. | Maitre de la Chapelle | et | Directeur de la Musique | a | Leipsic. | ecrite par Madame | Bachen. Son Epouse."7 Because no original autograph exists for the Suites, the exact date may forever be a mystery; however the idea of the Suites being composed circa 1720 is a likely assumption.

After Bach's death in 1750 his manuscripts were divided between his four sons and second wife, Anna Magdalena. ${ }^{8}$ It is possible that during this transitory period, the Suites were mislaid or sold on to another owner. Because of the unknown whereabouts, we can only consult five sources today: four $18^{\text {th }}$ century manuscript copies and the first edition published in the early $19^{\text {th }}$-century. The earliest known copy is by Johann Peter Kellner dating from 1726. Many reports speculate that Kellner was personally acquainted with Bach himself, however there is no definite evidence pertaining to this. It is uncertain why Kellner decided to write out the Suites, but it is clear that he did prepare a lot of Bach's music, much of which has become the only known source or earliest surviving record we have today. The second manuscript dates shortly after Kellner's, and is probably the most important source out of the five we have available. The autograph of Anna Magdalena Bach (J. S. Bach's second wife) originated between 1727 and $1731 .{ }^{9}$ The importance of her source is due to her close personal ties with the composer, as well as being a faithful copyist of many of his works. Her manuscript of the Suites is thought to be a copy prepared for Bach's pupil Schwanberg.

The third source, found in the collections of Johann Christoph Westphal's estate around 1830, is thought to have been prepared by two anonymous copyists in the second half of the $18^{\text {th }}$ century. Another anonymous version from Vienna makes up the fourth source available. Research has shown that this manuscript came from the latter part of $18^{\text {th }}$ century and is most likely of northern or central German origin. ${ }^{10}$ The fifth source is the first edition published by Janet et Cotelle in Paris around 1824. In this edition, Louis Norblin is mentioned, who is claimed to have discovered the Suites in Germany after undertaking research on them. The existence of the manuscript on which this edition is reputedly based cannot be verified.11 These sources are important references for editors and performers as they provide the only record that Bach's masterpiece ever existed. However, that being so, by analysing and comparing other works by both the copyists and Bach's own hand, many discrepancies can be found between of each of the sources.

\footnotetext{
7 Bettina Schwemer \& Douglas Woodfull-Harris, 6 Suites a Violoncello Solo senza Basso BWV 1007-1012 'Text Volume' (Germany: Bärenreiter Kassel, 2000), p. 4.

8 Rhiannon Thomas, Johann Sebastian Bach's Unaccompanied Cello Suites (BWV 1007 - 1012) Sources, Editions and Interpretations. (Wellington: Victoria University, 1996), p. 4.

${ }^{9}$ Bettina Schwemer \& Douglas Woodfull-Harris, 6 Suites a Violoncello Solo senza Basso BWV 1007-1012 'Text Volume' (Germany: Bärenreiter Kassel, 2000), p. 4.

${ }_{10} \mathrm{Ibid}$.

${ }^{11}$ Ibid.
} 
Which instrument Bach intended for the sixth and final suite remains an unresolved question. The sources, with the exception of the Kellner copy, give some insight into the instrument required for this particular suite by including 'à cinque cordes' preceding the Prelude. Following this indication specifically in the Anna Magdalena Bach MS, are five notated pitches: C2, G2, D3, A3 and E4.12 Other than this small piece of information, the specific instrument is still undetermined. Many musicologists have delved into this question and three plausible instruments come to the foreground: a five-stringed violoncello, violoncello piccolo or a viola pomposa. A myth that Bach invented the latter instrument is noted by author Dmitry Badiarov, who then goes into detail about conflicting augments in literature about the intended instrument.13 However, Gordon James Kinney suggests that Bach never called for this particular instrument outright in any of his works, apart from the violoncello piccolo, to which nine cantatas can be attributed, between 1724 and $1725 .{ }^{14}$ The fact that the cello Suites were written before these dates, has led many to believe that No. 6 was for a different instrument. ${ }^{15}$ Mattheson and Leopold Mozart described at the time there being players who added a fifth string to a violoncello when required. Also in support of this is Nathan Davis who states “...evidence points to the fact that where he had a good violoncellist available, as at Cöthen, he was much less inclined to use the violoncello piccolo."16 Although this statement may be true, it is also known that a proficient viol player resided there.

Modern performances of the Sixth Suite are played with either a standard four-string cello, or one that employs a fifth string. The former is seen more frequently in performance practice today and will be used for the performance component of this exegesis. However, the level of technical skill required from the performer is much greater when there is no fifth string. Many awkward positions are created from the lack of an E string and thus employing the use of thumb position as well as having advanced technique is crucial for the execution. Four out of five of the sources do not give any performance directions such as fingering suggestions to overcome these difficult passages, particularly found in the Prelude. Editors and performers therefore are left to their discretion and many variations in fingering patterns can be found in the numerous publications of the Suites. 


\section{PART ONE}

\section{OPENING PHRASE | Bars $1 \& 2$}

The first two bars of the Prelude from the Sixth Suite are exactly the same. Many editions use contrasting dynamics to create variance between bar one and two, some include different fingering suggestions and across the editions there is a range of different bowing markings.

The main feature found in this two-bar motivic passage is a D pedal note which immediately highlights the key in which Bach is writing and occurs on the second quaver of every dotted crotchet beat. The tails of the quavers are grouped accordingly, with the pedal notes written upwards and the moving melodic line downwards, indicating a change of string. Although one could argue that the first and second quavers of each beat form a double D pedal, it can be seen further on in this study (from bar 23) that the second quaver has a static nature whilst the other notes shift around this pedal. Many editors find a solution to convey an aural distinction by incorporating fingerings that encompass a variety of tone colours to give clear indication between both lines.

\section{Source $\mathbf{A}^{*}$}

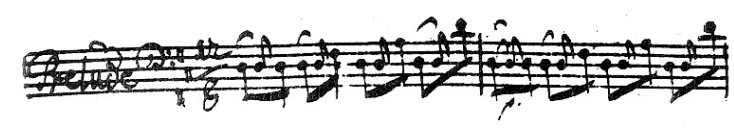

Source B*

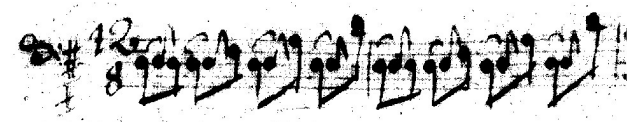

Source $\mathbf{C}^{*}$ Acinguecordes

* A. Anna Magdalena Bach, c. 1730.

${ }^{*}$ B. Johann Peter Kellner, 1726.

${ }^{*}$ C. (Anonymous) Johann Christoph Westphal, c. 1750.
Source D*

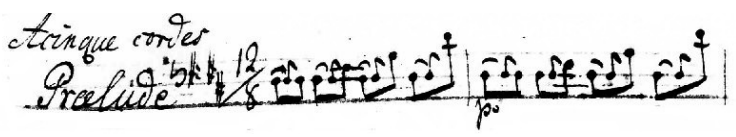

\section{Source $\mathbf{E}^{*}$}

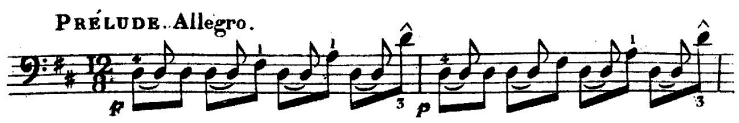

${ }^{*}$ D. (Anonymous) Vienna, Late $18^{\text {th }}$ Century.

${ }^{*}$ E. First edition. Louis Norblin. Janet et Cotelle, Paris, 1824. 


\section{HUGO BECKER}

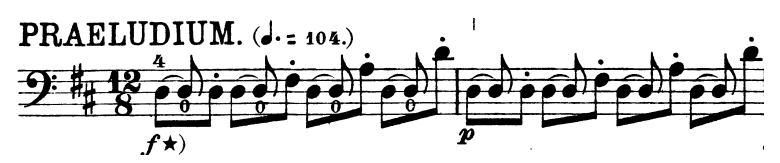

Hugo Becker includes minimal fingering suggestions in the beginning two-bar phrase of the Prelude. For the very first note the performer is instructed to start with a fourth finger on the G string, however the rest of the moving line within this passage has no finger indications. It is therefore assumed that the cellist will remain in second position for the duration of the two bars. The notes A3 and D4 toward the end of the bar are ambiguous as to which position on the cello to utilise because of the lack of fingering performance marks. In this instance there are several possibilities and it is left to the player's discretion to choose which one is most preferable. Some possibilities include but are not limited to: a stopped fourth finger on the D string to play the pitched A and a second finger on the A string to play the pitched D, or an open A string and a D harmonic with a third finger. A combination of these two would also be satisfactory.

It is immediately evident from a visual point of view that the pedal line differs from the moving melodic line. Becker specifically includes a '0' below each D pedal quaver note that occurs; directing the cellist to play the accompanying line on the open D string. Aurally, this creates a difference between the two lines as the open string has a more vibrant and resonant quality than a stopped note on the cello. ${ }^{17}$

\section{FRIEDRICH DOTZAUER}

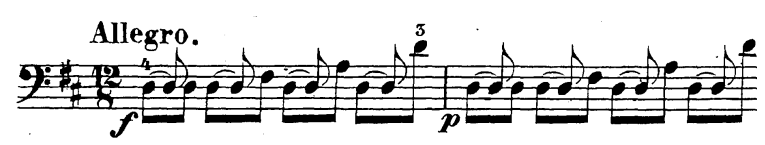

Like the Becker edition, Dotzauer begins the Prelude with a fourth finger. No other fingering suggestions are given except on the very last D quaver note in bar one, which is notated with a third finger. It is uncertain whether this particular note is meant to be played on the A string, or as a harmonic on the D string. The former is more likely considering there is no harmonic performance mark ${ }^{\circ \prime}$ notated below the fingering ' 3 '. This however creates unease for the performer as a stretch consisting of a whole-tone between the third and fourth finger is required in order to reach the last $\mathrm{D}$, or a semitone shift to extended first position. The latter option of a harmonic on the D string would be satisfactory if a quick hand position change could be done efficiently and smoothly, although Whitcomb suggests that playing only one note in one position should be avoided.18

\footnotetext{
17 Jeffery Kite-Powell, 'A Performer's Guide to Seventeenth-Century Music.' (Indiana: Indiana University Press, 2012), p.276. 18 Benjamin Whitcomb, 'Strings 101: Music \& Musicians - World of Possibilities: Learn to Devise the Best Cello Fingerings.' Accessed August 30, 2013. http://search.proquest.com.helicon.vuw.ac.nz/docview/1409812?accountid=14782.
} 


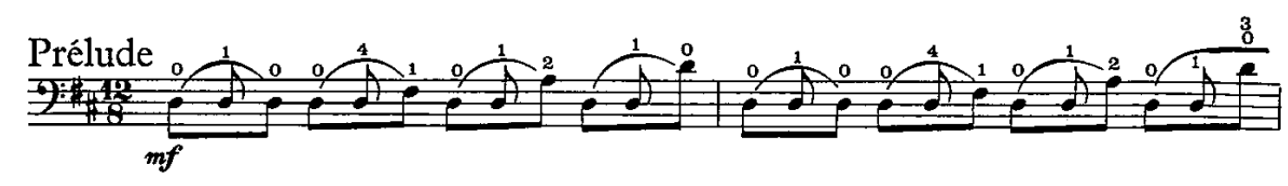

It is immediately evident that Jacqueline du Pré's edition of the Prelude is unique among the ten chosen for comparison. Not only has the editor meticulously detailed a fingering above each note in both bars (with the exception of the first quaver of beat four in bar one); she has also started the phrase on an open D string, which differs from the other nine editions. This reverses the role of the two lines within the phrase as the pedal note is now played as a stopped note on the G string, rather than the open D string as seen in other editions.

The hand positions during this two-bar passage change frequently. Unlike most other editions where a fingering pattern is suggested to retain efficiency of movement, i.e. to remain in one position on the cello, du Pré seems to change or extend the hand placement in every group of three quavers. These hand position changes, although unnecessarily frequent, follow Whitcomb's general principle of shifting positions after an open string. ${ }^{19}$ At the beginning of the bar, a first finger in fourth position is indicated for the first pedal D note. However the second time the pedal note occurs, it is notated with a fourth finger, which changes the hand to second position, allowing the first finger to stop the next quaver note (F sharp) on the D string. The third D pedal note switches back to fourth position on the first finger, but instead of playing the adjacent A with the same finger, du Pré follows the principle of using a neighbouring finger to execute a clean fifth. ${ }^{20}$ Although the last pedal note is also specified with a first finger, a stretch is needed to reach the D harmonic. Both bars one and two have identical fingering suggestions even though there appears to be a misprint with a fingering ' 0 ' left out in bar one.

\section{PIERRE FOURNIER}

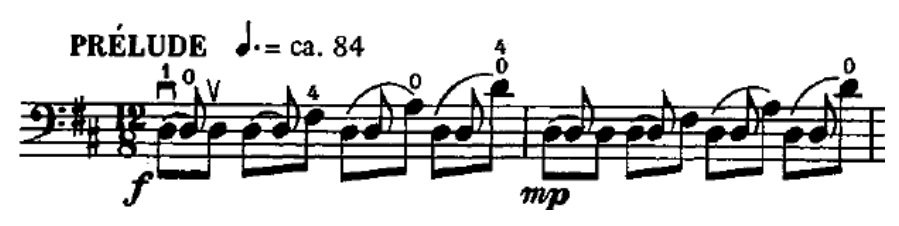

The few fingering suggestions printed in Fournier's edition appear to be included for left and right hand co-ordination and efficiency. For example, the fourth finger stretch to the F sharp on the G string in the

\footnotetext{
${ }^{19}$ Benjamin Whitcomb, 'Strings 101: Music \& Musicians - World of Possibilities: Learn to Devise the Best Cello Fingerings.' Accessed August 30, 2013. http://search.proquest.com.helicon.vuw.ac.nz/docview/1409812?accountid=14782. 20 Ibid.
} 
last quaver of beat two, and again with the same stretch to the D harmonic at the end of bar one, allows the hand to stay solely fixed in the extended fourth position. This minimalistic approach simplifies the movement in the left hand as no shifting is required, thus ensuring more focus is placed on the string crossings and general movement in the bow arm. Fournier tries to employ a resonant sound throughout this two-bar phrase by including open strings and harmonics where possible.

\section{FRITS GAILLARD}

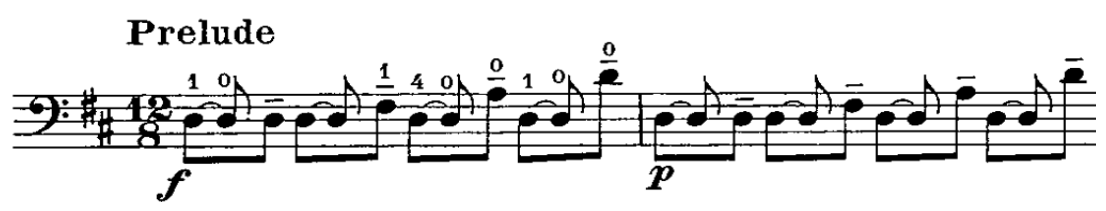

In this 1939 edition, the placement of the hand begins in fourth position on the G string with a first finger on a stopped D. Immediately following, the player is instructed to use an open string on the D pedal note so that an aural difference is created between the moving and static lines. The next three quavers in the bar do not have fingering indications thus it is assumed that the performer will stay in fourth position on the cello and repeat the fingering pattern given, with a first finger on the moving line and an open D for the pedal note. Rather than staying in fourth position for the F sharp and stretching to it with a fourth finger on the G string, the whole hand shifts back a minor third to second position on the D string and a first finger is suggested for the note. Keeping to the basic principle of shifting after an open string, ${ }^{21}$ Gaillard does not change positions until the open A string on the last quaver of beat three, where he suggests to go back to fourth position like the beginning of the bar.

Overall, Gaillard's use of open and harmonics is a similar approach to Fournier's edition. With no fingering indications marked in the second bar, it is assumed that this pattern is repeated or a variation can be used at the performer's discretion.

\section{FRIEDRICH GRÜTZMACHER}

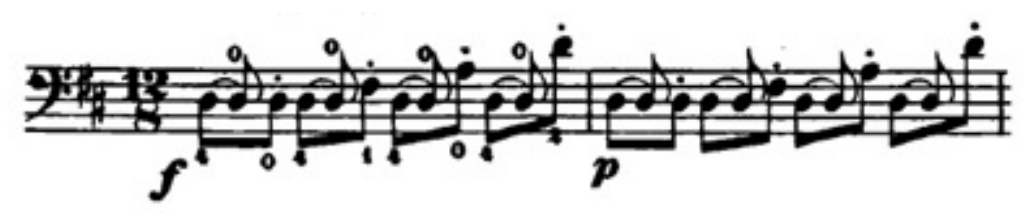

This edition has identical fingering suggestions to Julius Klengel's.

\footnotetext{
21 Benjamin Whitcomb, 'Strings 101: Music \& Musicians - World of Possibilities: Learn to Devise the Best Cello Fingerings.' Accessed August 30, 2013. http://search.proquest.com.helicon.vuw.ac.nz/docview/1409812?accountid=14782.
} 


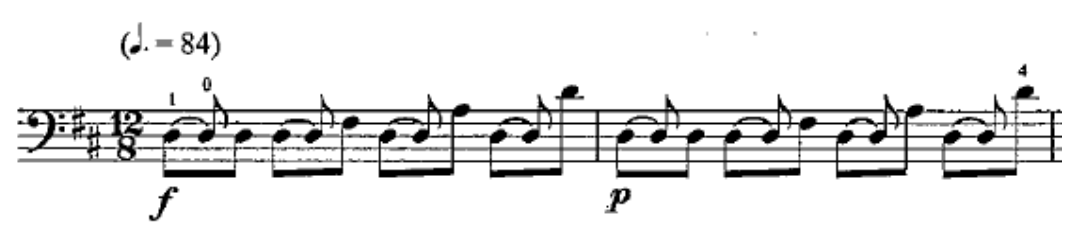

Few fingerings are included in this recent edition by cellist Tim Hugh; it is left to the performer's discretion as to what he or she prefers. However, a total of three fingerings over the two-bar passage are notated, as the editor sets up the hand placement for the performer by starting on a first finger on the G string and then crossing strings over to the open D for the second note. The last quaver, D4 in the second bar, changes to a fourth finger, making sure that the performer goes back into first position for the bars to follow.

\section{JULIUS KLENGEL}

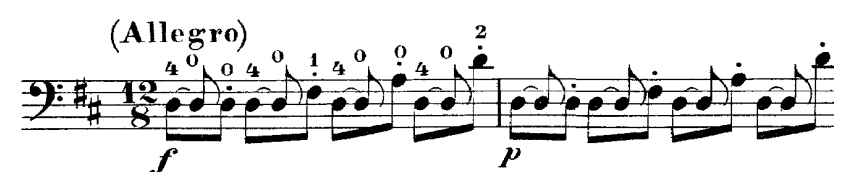

It is apparent from the beginning phrase of the Prelude that this editor has given a lot of thought to the performance directions. Every note in the first bar is detailed with a fingering suggestion thus making it obvious to the player the hand placement that is required. For instance, the first D in every group of three quavers is specified to be played with a fourth finger on the $G$ string, ensuring that the performer's hand is set up in second position and remains there for the entire motivic passage. The placement of the hand being in one position makes the playing aspect more efficient for the performer with the string crossings. For the hand to be fixed in one place for the duration of this repeated two-bar sequence, the co-ordination between the left and right hand is simplified.

The pedal D motive is accentuated in the Klengel edition as every time it appears it is to be played on the open D string, hence the fingering ' 0 ' written above the D quaver note. The resonating sound of an open string on the cello allows the pedal note to have a ringing quality. However, Klengel does not reserve the open D string just for the pedal note alone; the repeated D quaver note directly following is also specified with a ' 0 ' and it is part of the moving line. Choosing to repeat the open string on both the moving and pedal line suggests that the editor did not intend for a particular aural contrast between the two; but merely wanting to create an open and ringing sound throughout the phrase. The second bar is exactly the same with no change in fingering suggestions. 


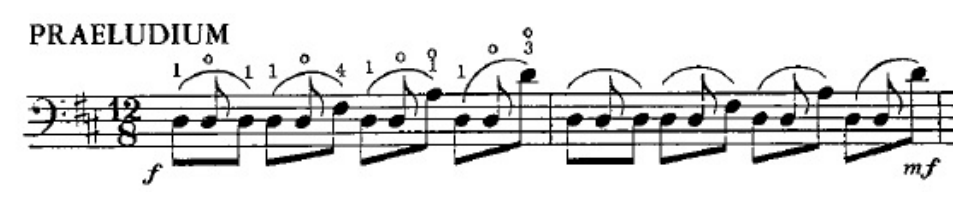

In bar one, each note is specified with a fingering. These suggested directions are identical to the Fournier edition, however on the last quaver of the third beat of the bar, the A3 note is given two fingering options; one being played as an open A string and the other a stopped note with a first finger on the D string. Since no fingerings are included in the second bar, it is assumed that the player repeats the fingering pattern given in bar one.

\section{JÁNOS STARKER}



This edition is similar to Rosanoff's version, but with less fingering notated. The hand of the cellist is directed to be set up in fourth position, with a first finger on the G string. A stretch of a major third to the F sharp is followed with a stopped first finger on the A3 quaver and a third finger harmonic on D4. The second bar has no fingering suggested.

\section{AUGUST WENZINGER}

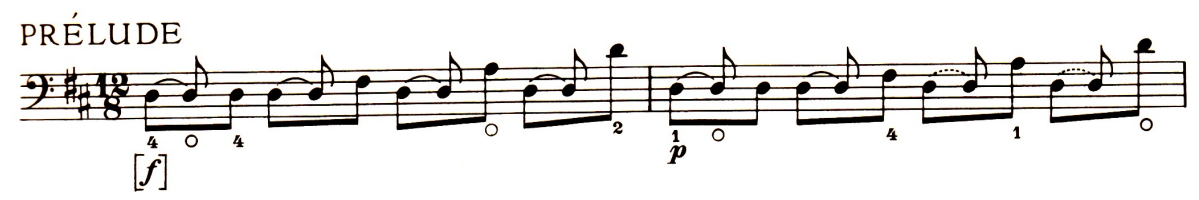

The interesting aspect about Wenzinger's publication is the abrupt change in the fingering pattern between bars one and two. Although Wenzinger follows the common approach seen in most of the editions in this study, with the moving line played stopped on the fingerboard and the pedal note on the open D string, the editor takes it one step further by including fingerings that complement the dynamic marking. Although this study is specific to fingering performance directions, it is worthwhile to note that across the Suites sources and editions, the first bar typically has a forte dynamic marking followed with a piano in bar two. This 'echo' effect is helped within this edition by a few crucial hand placement changes and two examples demonstrate how fingering can support these changes in dynamic marking. 
The F sharp quaver in the second beat of bar one is assumed to be executed with a first finger on the D string given the hand position set up in beat one. In the second bar however the same note is notated with a fourth finger on the G string. The different registers on the cello emit a variety of timbres, and thus playing on a higher position on a low string produces a softer and less strident sound than the same pitch in a low position on a high string. This change is also seen in the third beat of bar one where Wenzinger uses an open A string for the A3 quaver. A resonant and loud sound is created from the use of an open string, an effect that has been discussed in previous editions. The same note in bar two however is suggested to be played in fourth position with a stopped first finger on the D string, creating a dampened effect.

\section{SUPERTONIC MODULATION | Bars 23 - 32}

Shifting through the circle of fifths, the passage between bars 23 and 32 has modulated to the supertonic key of $\mathrm{E}$ minor and loosely resembles the material seen at the beginning of the Prelude. ${ }^{22}$ Like the start of the movement, a pedal dominates the passage however this time it is centred around the note E. If played on a five-stringed cello, this section of the Prelude would be fairly straightforward as the pedal note could be executed on the open E string. On a standard cello, it is much more difficult to play the E4 note simultaneously with the moving melodic line as the cellist has to compensate for the missing string, often resulting in the use of the thumb. Editors have included a variety of fingering suggestions to overcome this barrier, largely using the A and D strings, or the D and G strings.

\section{Source A}

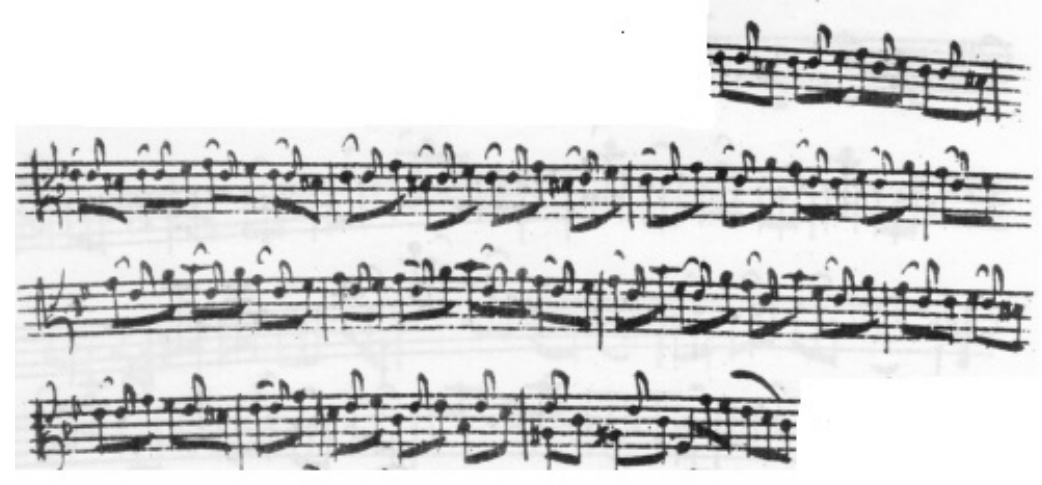

22 Daniel E. Prindle, 'The Form of the Prelude to Bach's Unaccompanied Cello Suites' (Boston: University of Massachusetts, 2011), p. 75. 
Source B

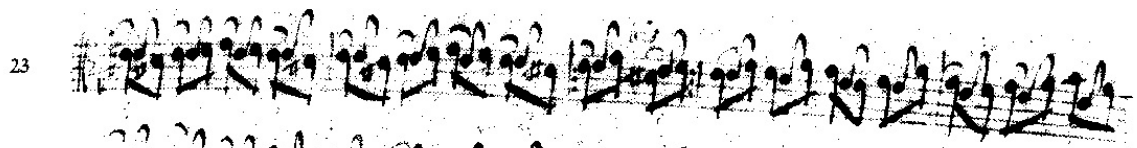
-
$32 \quad y+y+49$

Source C

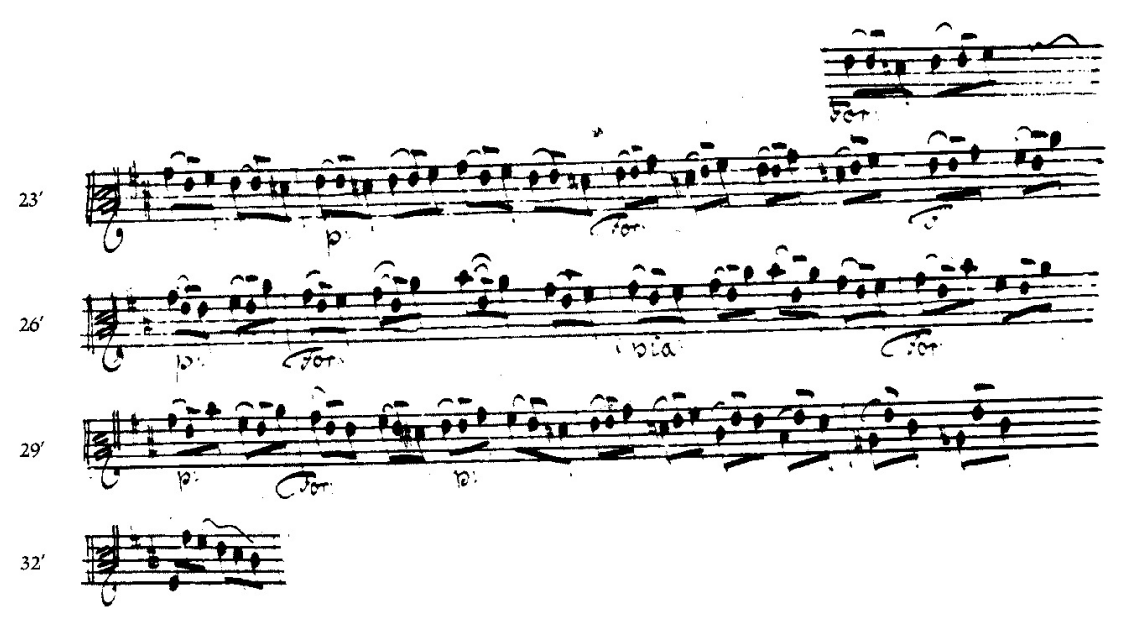

Source D

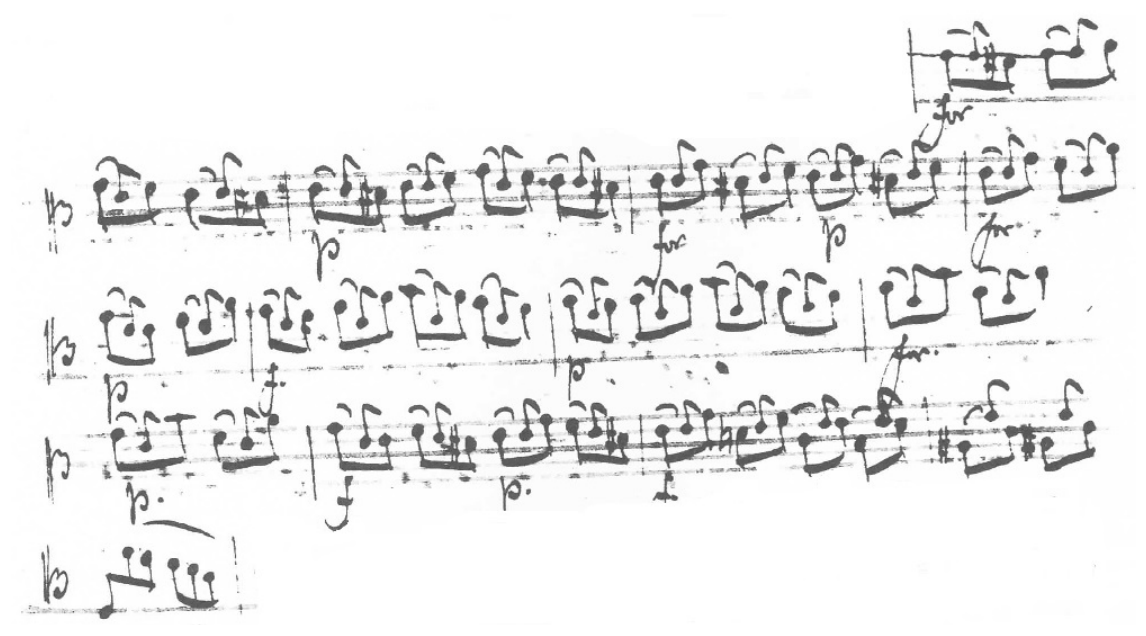




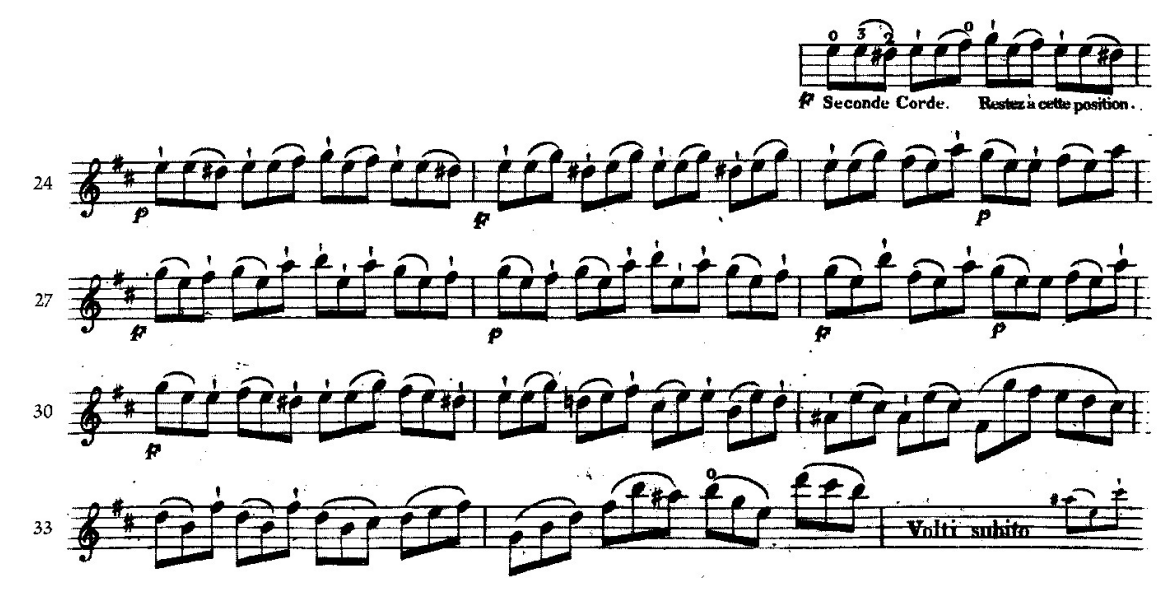

HUGO BECKER

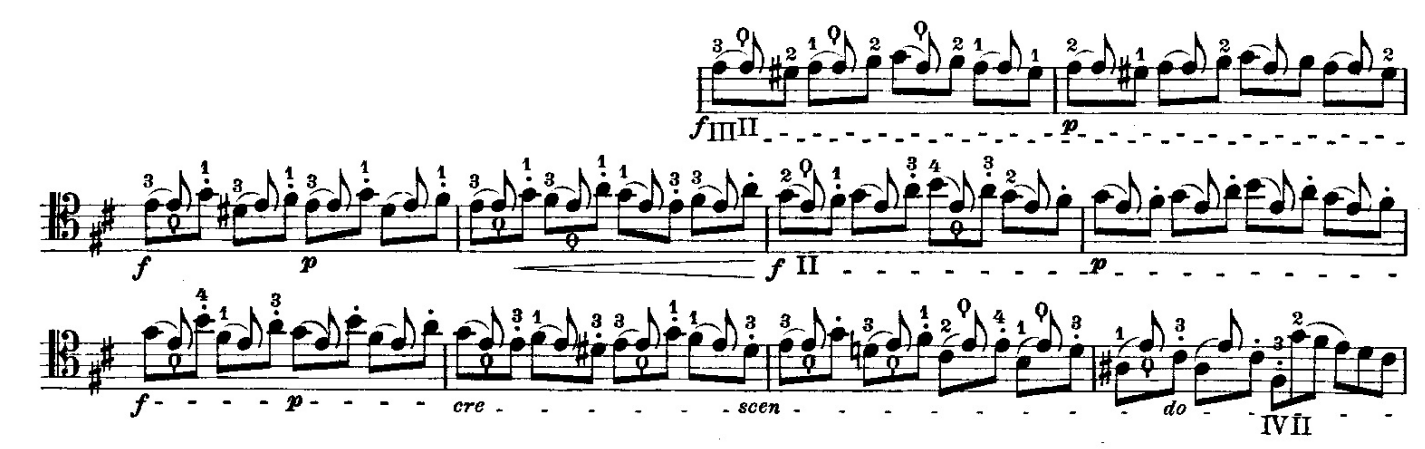

Becker has again incorporated a fingering pattern that helps to differentiate between the pedal and moving lines. In the previous passage (bars $1 \& 2$ ) used for this study, the editor reserves the pedal note for the open D string. However, there is no E string on a standard cello, thus Becker has included the use of the thumb to play the E pedal note in this phrase. Starting with a third finger on the G string in 'thumb position', the E4 pedal note is then played on the D string. Playing this passage high up the fingerboard on these two strings creates a more compact hand position and is therefore more comfortable for cellists with smaller hands. Becker stays clear of suggesting fingerings that require the player to stretch their hand and this is evident with his inclusion of the fourth finger for the note E5 that occurs in bars 27,28 and 29. 


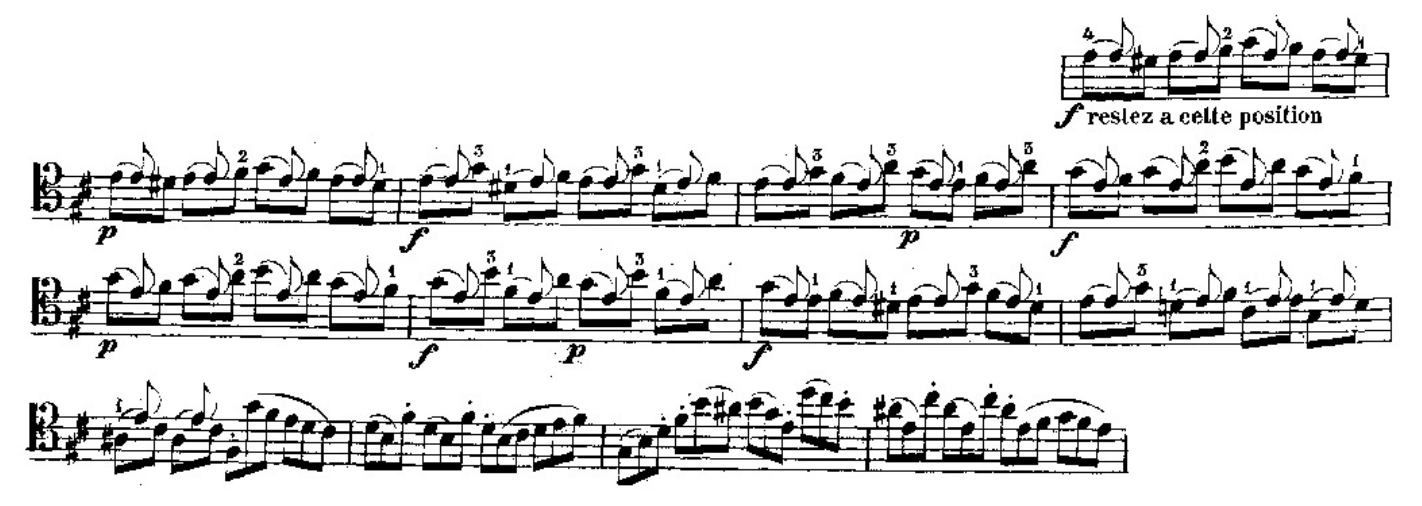

A fourth finger begins this 13-bar passage, however the choice of string is unspecified. At first look, it seems as if the passage should be executed on the A string, however the text 'restez a cette position' inserted underneath bar one suggests otherwise. If the placement of the hand is instructed to remain in one position, then playing this passage on the A string would not be possible. The same extract in the Grützmacher edition also includes a fourth finger as the editor instructs the cellist to begin in the high register on the G string. His fingering pattern may be what Dotzauer is trying to express.

JACQUELINE DU PRÉ
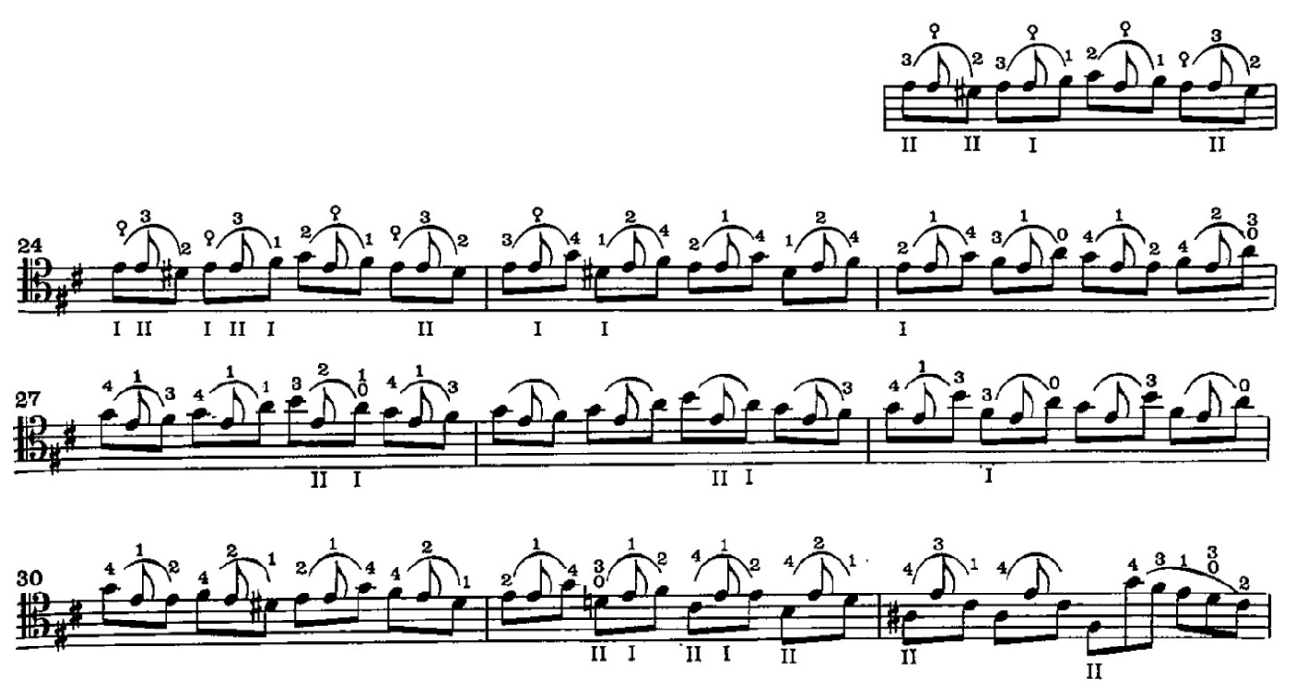

Du Pré has meticulously included a fingering suggestion above every note, with the exception of bar 28, where it is assumed that the player will repeat the fingering pattern in the previous bar. Starting on the $\mathrm{D}$ string, the cellist must stop the note $\mathrm{E}$ with a third finger. The thumb is then in position on the $\mathrm{A}$ string to stop the E pedal note. This fingering pattern is consistent for the first three beats of bar 23 before the editor changes the placement of the pedal note and puts it on the D string in order for a smooth step to the next note D, the last quaver of the bar. Bar 25 sees a shift in the hand position altogether, du Pré suggesting fingering which keeps the remainder of the phrase purely on the A string. 
This requires a lot of hand movement for the changes of positions: the fingerings suggested create a crawl-like effect up the fingerboard. This would be a good fingering for a player who is not comfortable with remaining in thumb position.

\section{PIERRE FOURNIER}

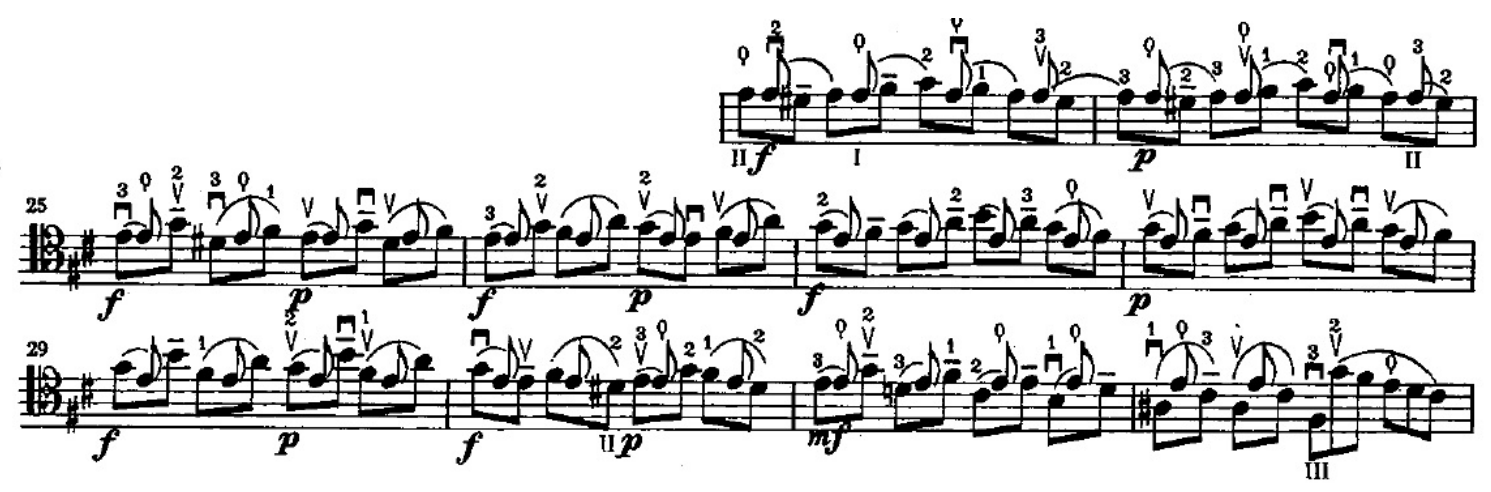

Fournier begins the first quaver in bar 23 with the thumb on the D string, resulting from the hand position already set up in previous bars. However, instead of remaining in this position and continuing the phrase on the D and G strings, as seen in the Becker and Klengel editions, a second finger is suggested immediately following the thumb E quaver. This allows the hand to play the remaining notes on the A and D strings. This is re-iterated with the symbols ' $\mathrm{\varphi}$ ' and 'I' on the second quaver of beat two indicating to the player that the thumb and hand position is on the A string. This change in position, although abrupt, correlates to the other performance directions notated in the score, particularly the slurring markings. Fournier's edition is unique in the way he phrases the return of the pedal note motif in the supertonic key. All other editions within this study begin bar 23 as a new phrase, emulating the start of the Prelude. This edition however has the return of the motif connected to a slur in the previous phrase from bar 21. The pedal note therefore begins the new phrase on the off-beat with a new slur, and in turn, is emphasised by a change in dynamic to forte where prior bars were piano. This has the effect of blurring the beginning of the phrase and the downbeat of the bar. 


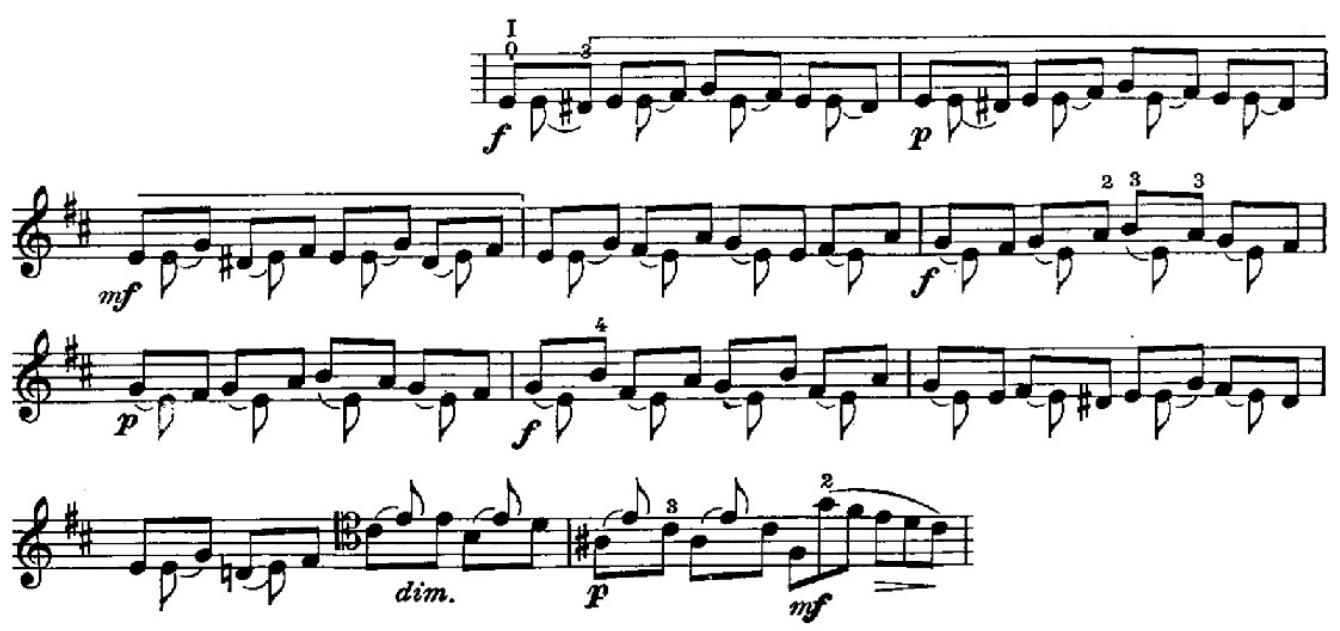

Unlike Fournier's edition, the hand position begins straight away on the A string with the thumb on the first E4 quaver note. Because the thumb is established on the moving line, it has not been reserved just for use on the pedal note and thus no differentiation is created between the two lines. Overall, few fingerings are included in this passage and those that are, are used specifically for shifting purposes.

\section{FRIEDRICH GRÜTZMACHER}

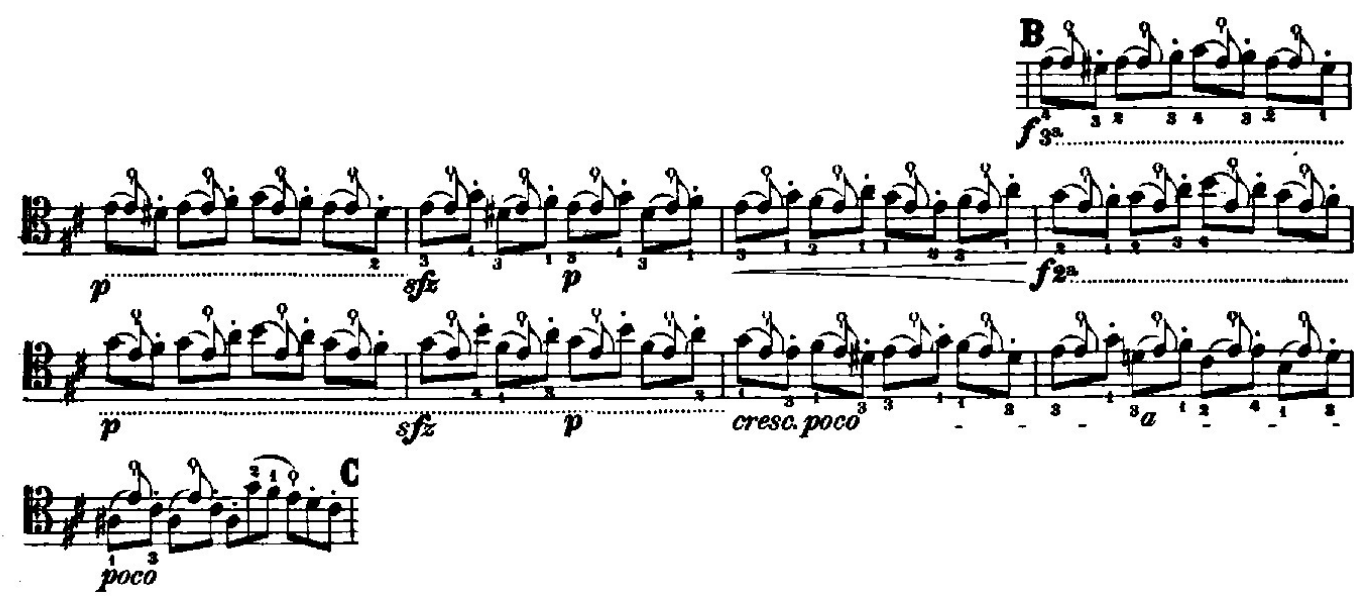

The first two bars suggest that the cellist play the passage on the G string starting with a fourth finger on the first E note. This is an interesting fingering pattern to use; covering the octave interval with a fourth finger and thumb. Starker suggests that when going into high positions on the cello, a third finger should be used instead of a fourth. ${ }^{23}$ The cellist states that an interval of an octave should be reserved for the third finger and thumb; however a fourth finger is feasible if the position is more comfortable for the performer. ${ }^{24}$ With the exception of Dotzauer's publication, no other edition in this comparative

23 János Starker, 'An Organized Method of String Playing' (USA: Peer International Corporation, 1965), p.30.

24 Ibid., p. 20. 
study has used this fingering on the G and D string. It is probable that Grützmacher included a fourth finger to help reach the E note more efficiently after playing the previous G note with a second finger on the D string. The editor throughout the entire passage is very specific with the placement of the thumb, with each E pedal note notated with the thumb ' $\mathrm{p}$ ' symbol.

\section{TIM HUGH}


Overall, very few fingerings are notated within the score and it is unclear which strings the passage is to be carried out on. The fingering pattern established, whereby the thumb is on the pedal note and the remaining fingers execute the moving line, could work either starting on the G string or the D string. After further examination, particularly in bar 32, the latter option of the D string seems more plausible. For instance, if the passage was already on the G string, the string indication 'III' notated would be unnecessary and the shift between the last quaver of beat two to the first quaver of beat three would be very large and awkward to play. On the D string however, a string indication would be required for the cellist to cross to the G string for the F sharp quaver.

\section{JULIUS KLENGEL}

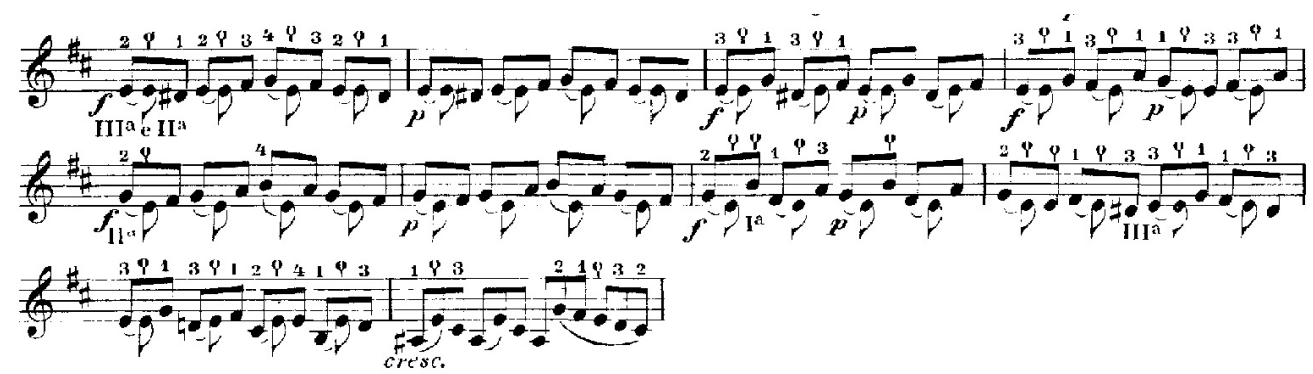


This passage within Klengel's edition is heavily notated with fingering suggestions. As well as these, the editor has also indicated the string he wants the performer to play on, which can be found in bars 23,27 and 30. The performer is instructed to start the passage with a second finger on the G string and then use the thumb to stop the E pedal note on the D string. In this higher register, the distances between pitches are smaller allowing the hand to be in a more natural and relaxed formation, contrasted with the extended hand required for the majority of the passage if it were placed on the D and A strings respectively. Throughout the entire passage the pedal note is played with a thumb on the D string and the remaining fingers are reserved for the moving melodic line.

\section{LIEFF \& MARIE ROSANOFF}
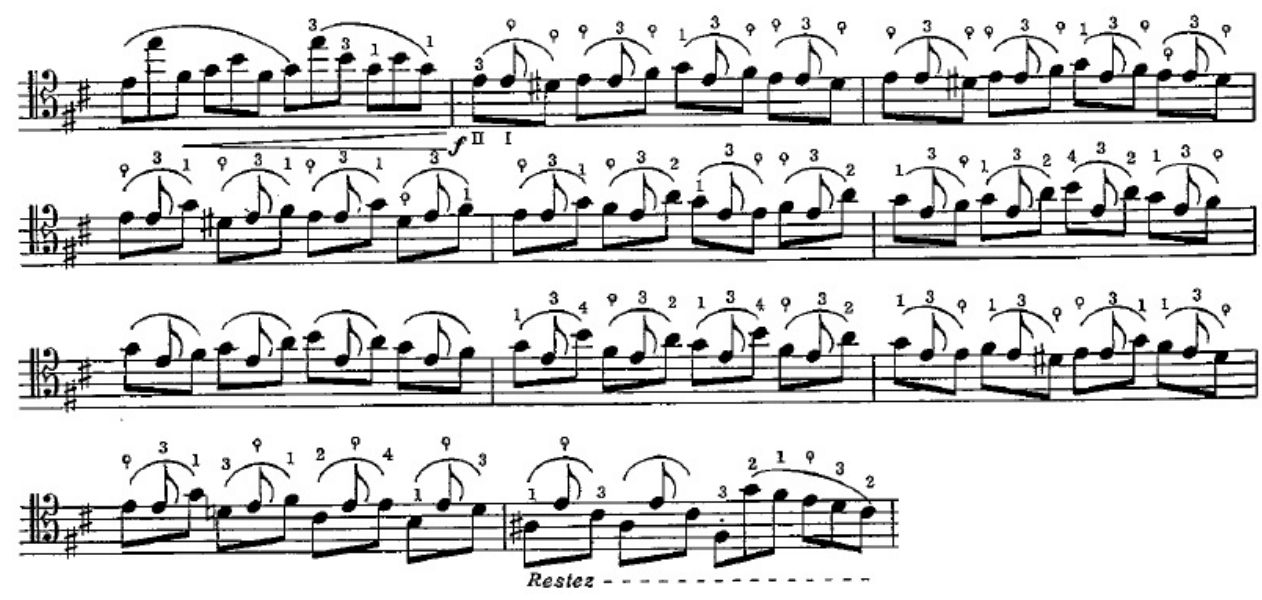

The Rosanoff edition is precisely detailed with fingering suggestions and it is evident that this passage from bar 23 to 32 is no exception. Most of the notes within the moving line, particularly in bars 23 to 26, are notated with the symbol ' $Q$ ', instructing the cellist to use the thumb. Generally, it is more common to have the thumb as an anchor for the remaining fingers or as a pivot point to help to change positions on the fingerboard. However in this edition, the opposite is enforced with the thumb moving both backwards and forwards for the majority of the melody while the hand and fingers remain in one position, the exception being the first finger on the G quaver note. This pattern changes from bar 27 where more fingers are needed to reach the higher notes. The E pedal note is continuously played with a third finger on the D string for the majority of the passage. It is evident that Rosanoff has incorporated a fingering system that is unique among most of the other editions seen in this study and has still allowed for both the moving and static lines to be independent. There are instances where Rosanoff has deviated from the general rule of using a third finger on the E pedal note, for example, the thumb plays the pedal note from beat two in bar 31 until the end of the extract. Nonetheless, the editor enforces that the two lines remain independent and are played with separate fingers. 

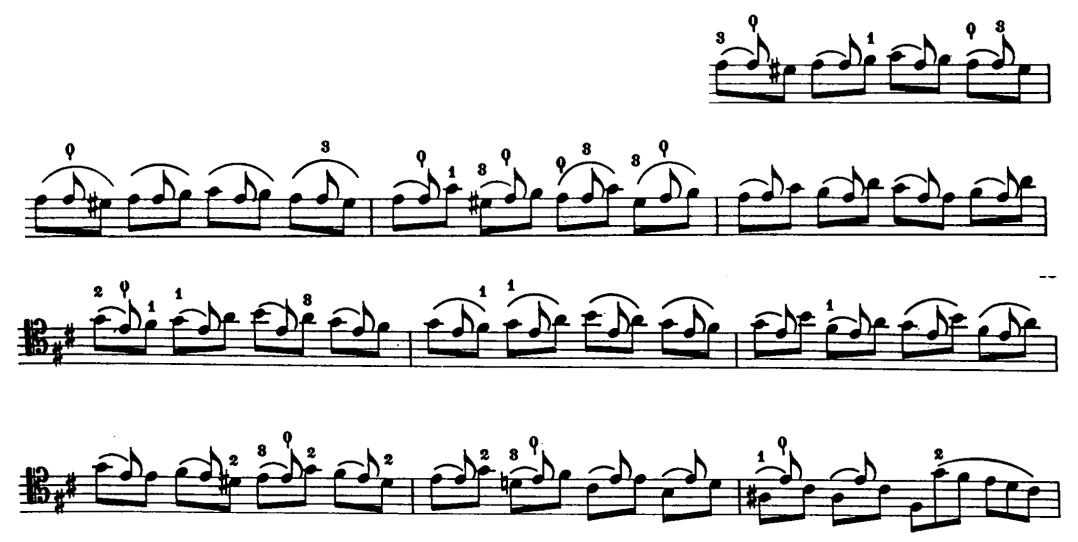

The fingering pattern suggested for this phrase could either work for the A and D string, or the D and G string. It is unclear which strings Starker wants the cellist to play on as there are no indications included within this publication, which also occurs in the Hugh edition. In bar 27, there is a first finger shift between the semitone of $F$ sharp and G, a fingering pattern that is repeated when these notes recur in the following bar and again with a variation in bar 29. This ensures that the cellist is more accurate when placing the quaver B5 note, as a systematic fingering of 1-2-3 in thumb position is preferable.

\section{AUGUST WENZINGER}
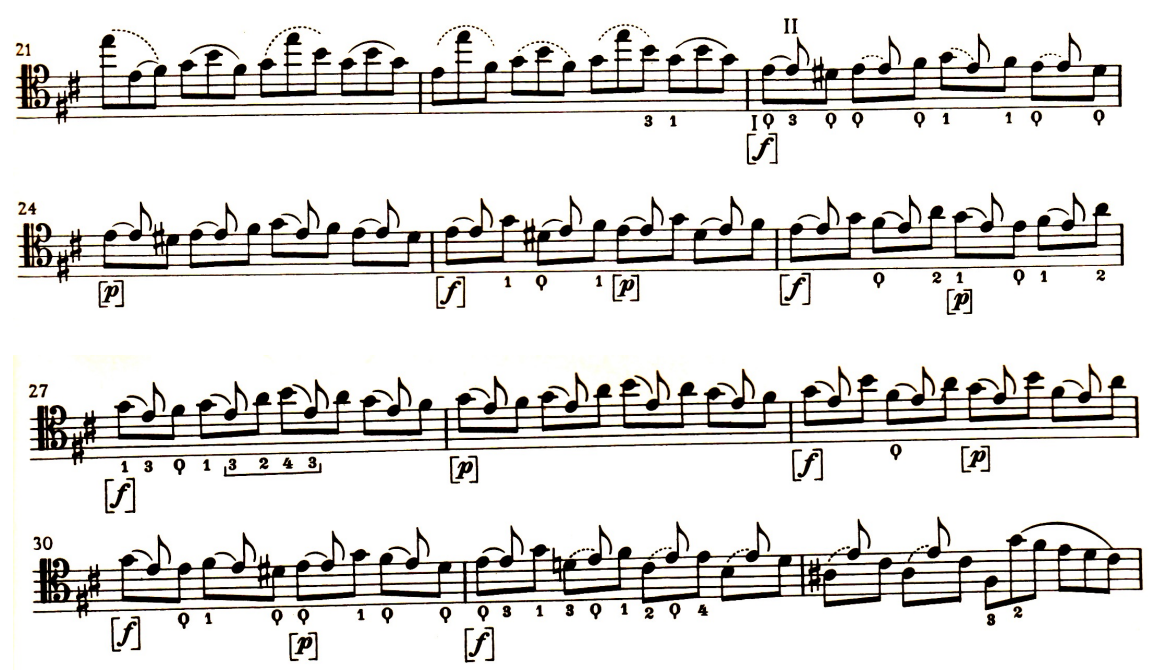

The fingering pattern that Wenzinger incorporates is similar to the Rosanoff edition with the thumb playing the majority of the moving line whilst the hand and fingers stay in position. Like Rosanoff, Wenzinger has indicated with a third finger that the cellist play the pedal note on the D string with a figure 'II' notated above the E. This ensures that the moving melodic line is predominately played on the A string. 
The last bars of the Prelude are primarily made up of ascending and descending scalic and arpeggiated figures. Bars 100 to the end outline a I-IV-V-I cadential sequence solidifying the D major key whilst the climax of the passage is found in bars 102 and 103 with two D5 quaver notes. Differences are apparent between the publications, as some editors prefer to use efficient fingering systems to reach the peak of the phrase, whilst others are inclined to suggest patterns that enhance the musical phrase.

\section{Source A}

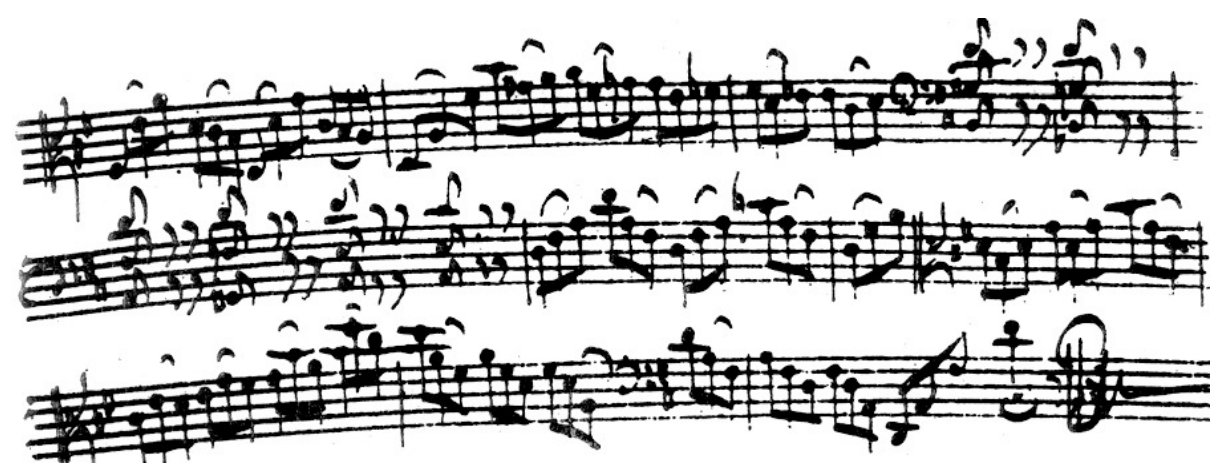

Source B

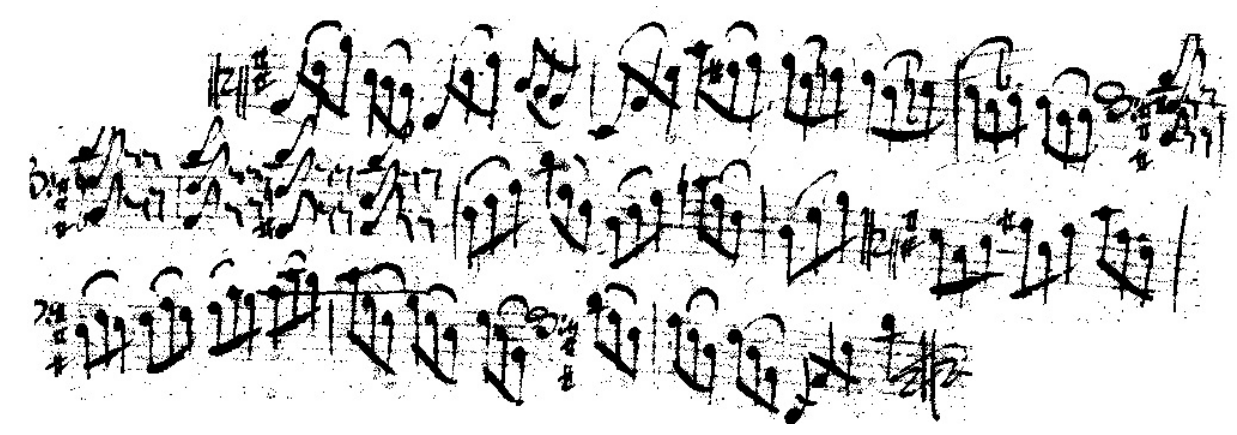

Source C

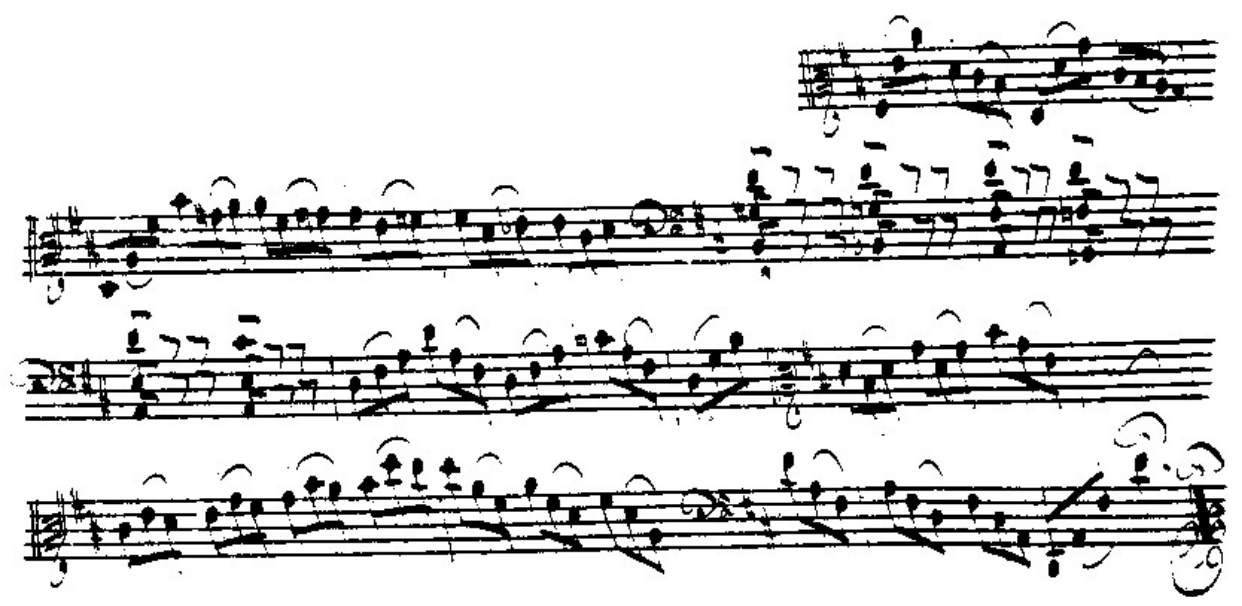




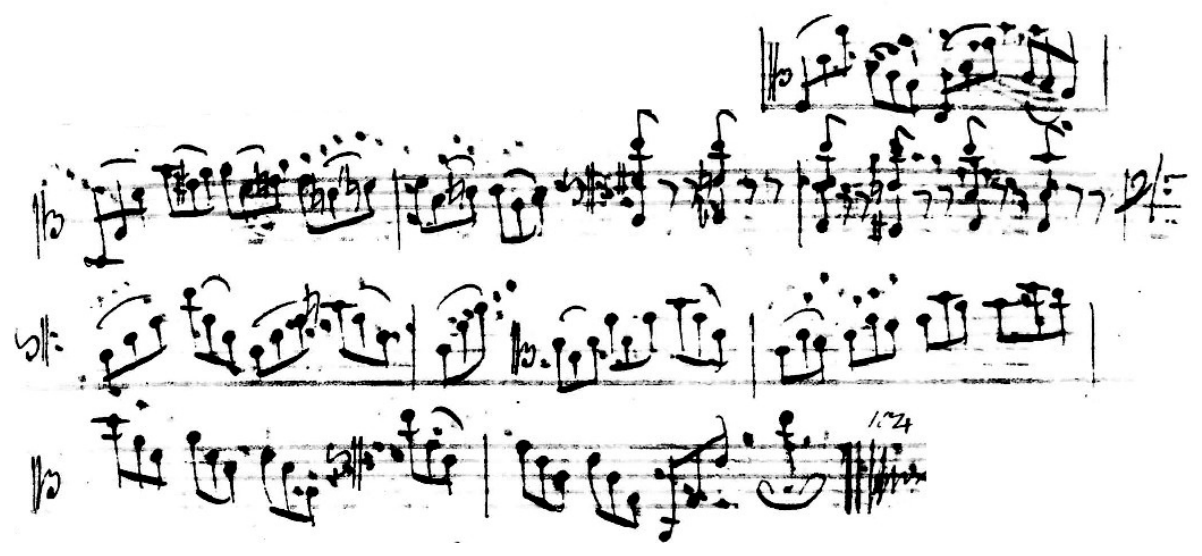

Source E

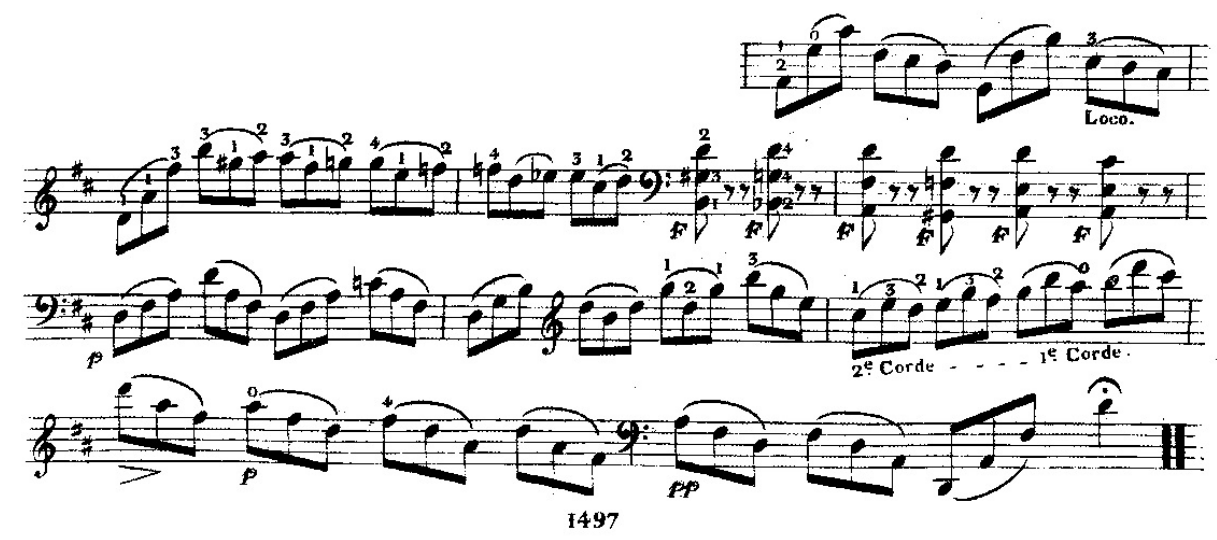

HUGO BECKER

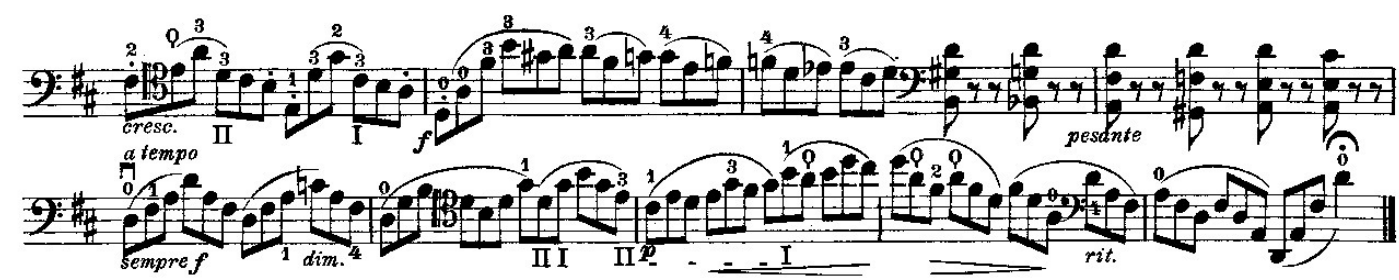

During the first three-note arpeggio of bar 96, Becker begins in first position and then changes to a thumb on the note E4. This fingering suggestion allows the cellist to efficiently stay in one hand position and, in this instance, play the next seven quaver notes over three strings (A, D and G) without shifting. It is possible to play this section without the use of the thumb; however several hand extensions would be required. Becker therefore adheres to Whitcomb's principle of a regular position taking precedence over an extended one, by including the thumb in this section. ${ }^{25}$ Instead of playing the remainder of bar 96 in thumb position, Becker suggests the cellist moves back into first position on the

25 Benjamin Whitcomb, 'Strings 101: Music \& Musicians - World of Possibilities: Learn to Devise the Best Cello Fingerings.' Accessed August 30, 2013. http://search.proquest.com.helicon.vuw.ac.nz/docview/1409812?accountid=14782. 
last beat with a third finger on the $\mathrm{C}$ sharp. This allows the player to execute the first two quavers of bar 97 on open strings, enhancing the printed forte ' $f$ ' dynamic marking created by the resonant sound.

\section{FRIEDRICH DOTZAUER}



Again there is limited fingering included in Dotzauer's edition however the suggestions that are found are identical to Becker's version. The only exception to this is the first quaver chord of bar 99 where the editor includes the fingers 1-3-4 to re-iterate that the chord should be played in first position covering the G, D and A strings.

\section{JACQUELINE DU PRÉ}
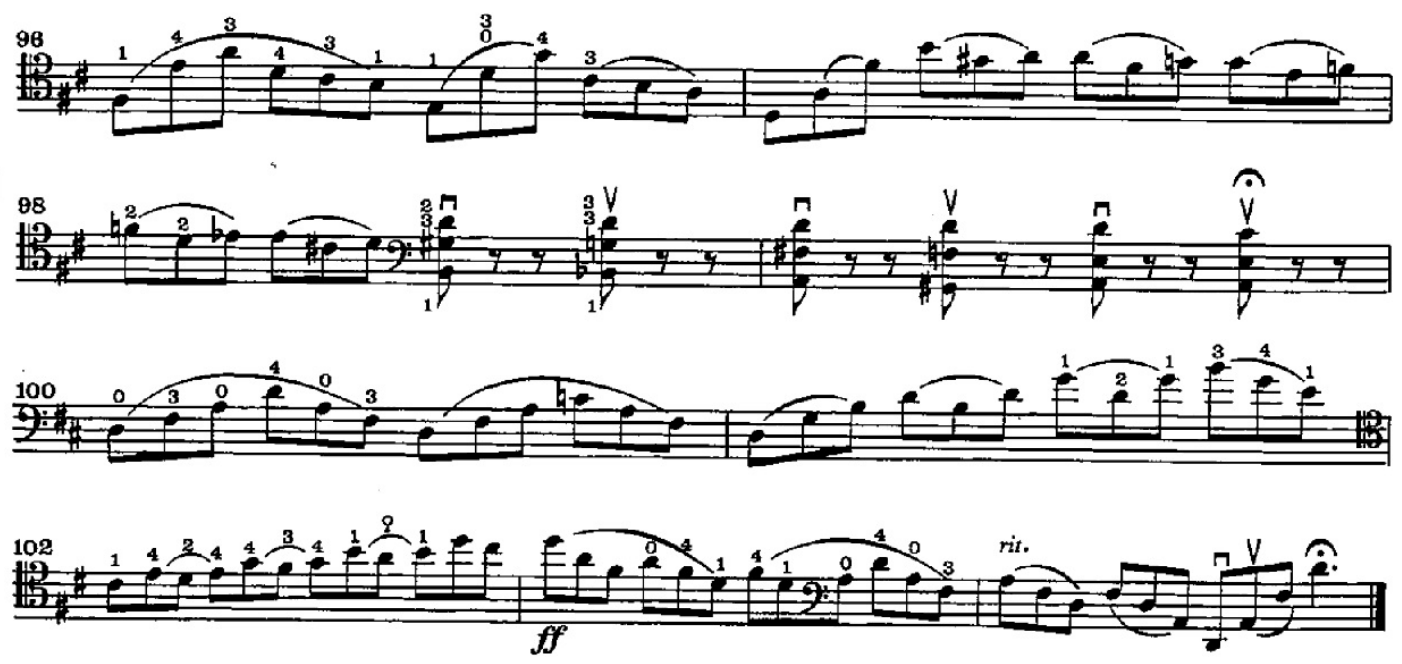

In previous bars leading up to bar 96, the hand position of the performer is set up in fourth position with the thumb anchored on E4. At bar 96, a first finger is notated for the F sharp however it is unclear whether the cellist is to remain in fourth position, or to shift back to second position because no string markings are indicated. It can be assumed that because of the fourth finger notated above the second quaver in bar 96, playing this passage in first position would be more comfortable for the average player although large leaps in hand positions on the A string would occur. The first finger on the F sharp makes Du Pré's edition unique as all other editions notate the same note with a second finger. More so, if the performer takes the first finger marking on the F sharp to be in first position, this edition will be the only one not starting in fourth position for this particular passage. 
Du Pré includes fingerings that often allow the performer to shift on the same finger, which is seen in bars 98, 102 and between 101 and 102. In bar 102, the slurs are moved over by one quaver beat, which is unique among the editions other than Fournier's version that also includes this marking. The fingerings coincide with this slurring where the performer is directed to change hand positions after each slur to help create a smooth line.

The first two of the six chords in this passage have instructed fingering. The top two notes of the second chord which make a fifth are both played with a third finger therefore du Pré does not follow the principle of using neighbouring fingers.

\section{PIERRE FOURNIER}

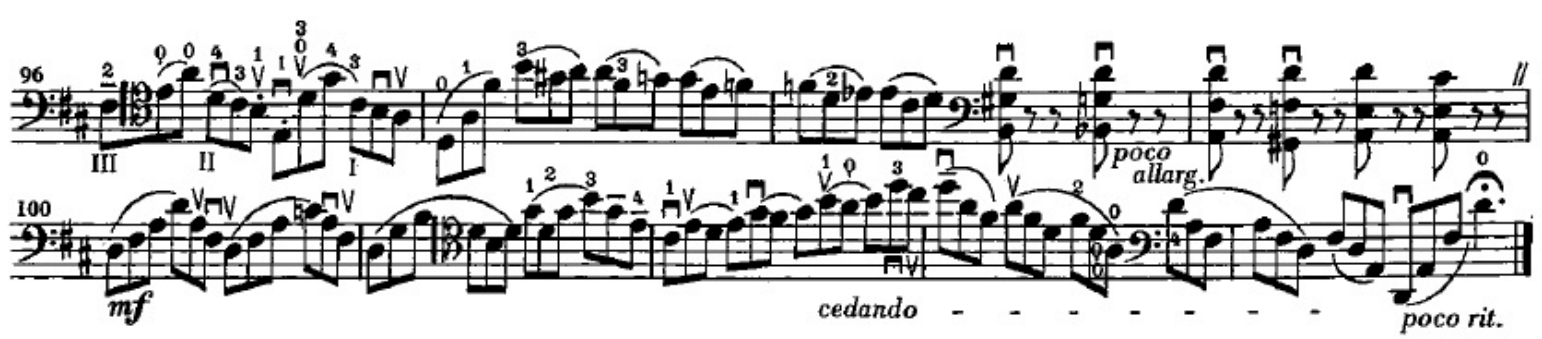

The

thumb is centred around the quaver note E4 in bar 96 and this position does not change until the last crotchet beat of the same bar where it is instructed that the cellist shifts to first position with a third finger stopping the $\mathrm{C}$ sharp. In most other editions in this study, the fingering changes on the beat or with the change of bow, which can help to stop the shifts from becoming audible. Fournier however shifts after the repeated note, seen in bars 97 and 98, which minimises the amount of hand position changes. Before reaching the peak of the phrase with the D5 quavers, Fournier shifts up the A string using a first finger. The very last note of the Prelude ends with a harmonic on the D string.

\section{FRITS GAILLARD}

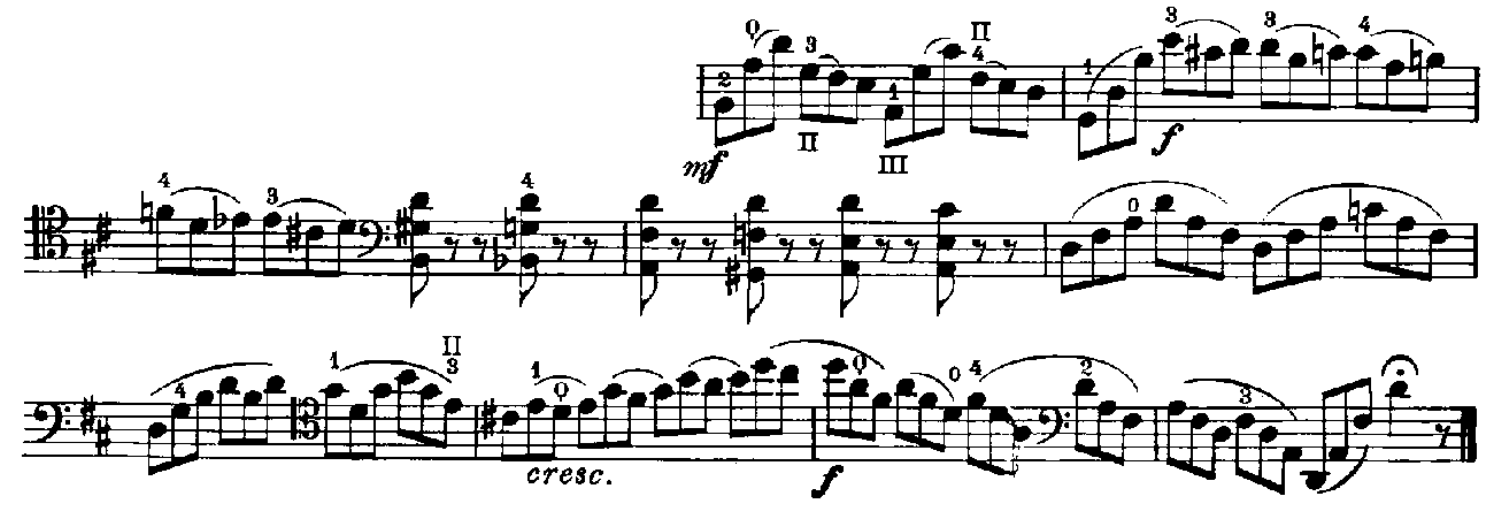

Bar 96 is predominately set up in thumb position starting with the second finger on the F sharp and the thumb on the E4 quaver note. This hand placement lasts until the fourth beat of the bar where it is then 
instructed for the performer to shift to fourth position with a fourth finger. In bar 97, the fingering changes after each group of three quavers from beat two in order to create a smooth descending line on the A string. With an open string notated above the A quaver note in bar 100, it is assumed that the cellist remains in first position for the arpeggios until halfway through bar 101. A third finger on the D string for the quaver note $\mathrm{E}$ allows the performer to prepare themselves for an easy transition onto the thumb in bar 102 which provides an efficient position for playing up to the peak of the phrase. It is not until the middle of bar 103 that the cellist goes back to fourth position on the A string with a fourth finger and then first position in the last bar to finish the Prelude.

\section{FRIEDRICH GRÜTZMACHER}



Grützmacher's fingering patterns are similar to those found in Fournier's edition. Firstly, the beginning of the passage starts with a second finger on the G string and then the thumb on the next quaver note which is a pivot until the last beat of the bar. Secondly, the editor includes the same fingerings in bar 97 and 98 minimising the number of shifts by changing after each repeated quaver note. Further on in this passage, the editor breaks away from what appears to be a similar fingering system to the Fournier edition, by including fingerings for the first two chords at the end of bar 98. These suggest that the cellist remain in the position set up in the first beat of bar 98 for the first chord and then shift back a semitone with a second finger on the B flat to play the second chord. In bars 101 and 102, instead of climbing up the A string to reach the peak of the phrase as seen in Fournier's edition, Grützmacher instructs the cellist to cross over to the D string. This efficiently minimises the total number of shifts as the notes fall predominantly under one hand position. Being in this register on the cello also softens the sound, thus accentuating the piano dynamic performance marking the editor has included before the crescendo to the climax at bar 103. 


\section{TIM HUGH}
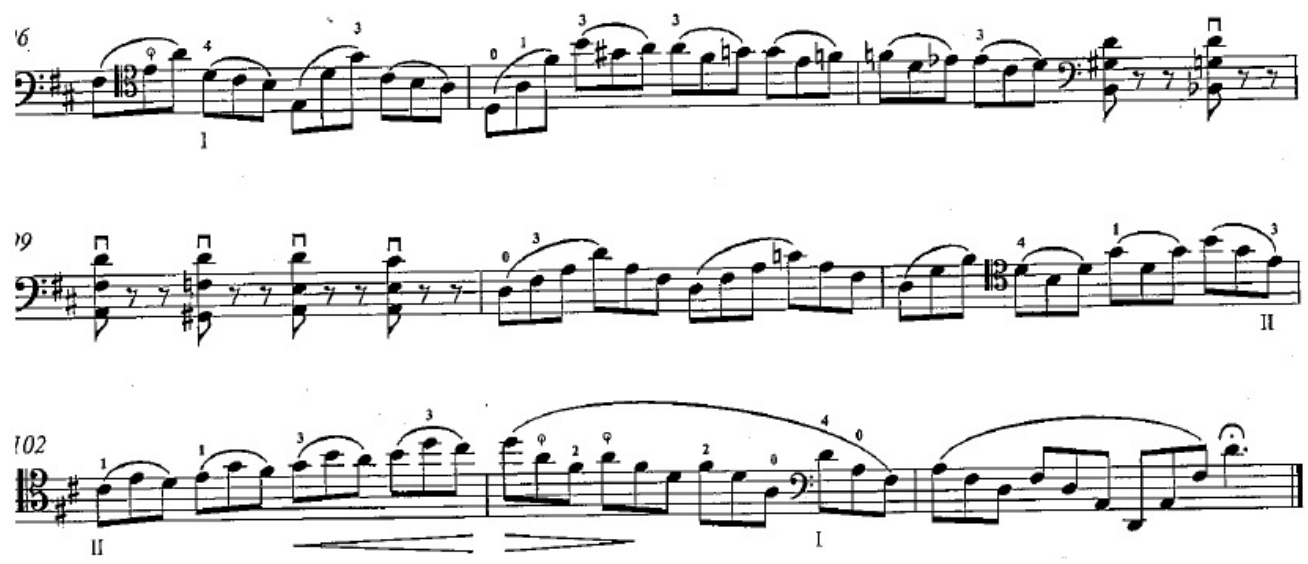

The Hugh edition begins bar 96 in thumb position but quickly changes to first position with a fourth finger on the A string in the second group of quavers. Like the other excerpts in this study of the Tim Hugh publication, there are very few fingerings included. The suggestions that are included in bars 102 and 103 are the same as Grützmacher's and Klengel's, as well as the majority found in the Wenzinger publication.

\section{JULIUS KLENGEL}

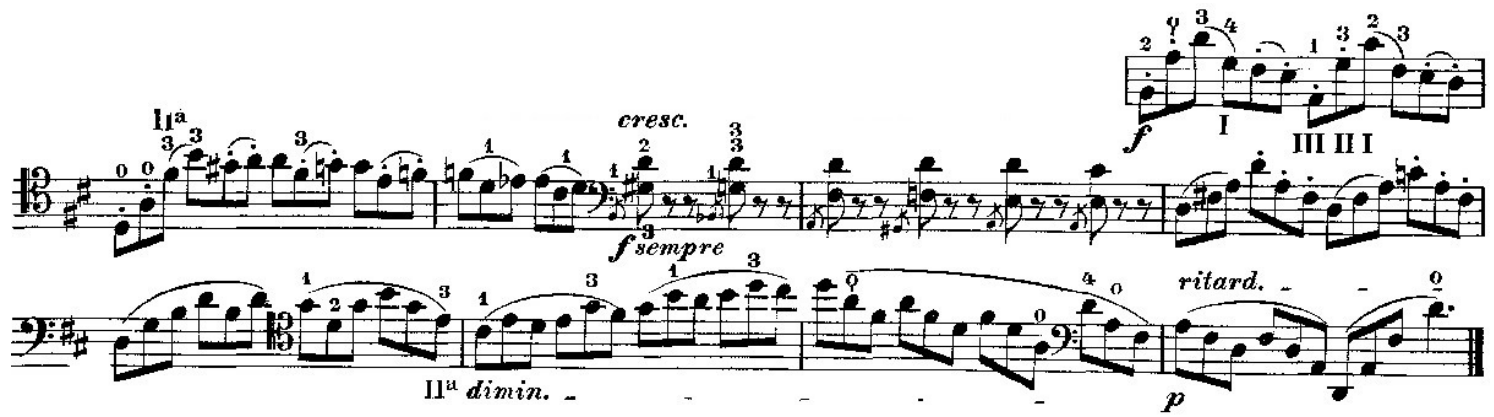

This passage in the Klengel edition begins with the thumb used as a pivot on the E4 quaver note as seen in most of the other editions in this study. However, this edition quickly goes back into first position on the second dotted crotchet beat with a fourth on the D quaver note. Instead of staying in the first position, the editor suggests with a first finger to play the E3 quaver note on the G string creating an awkward and perhaps unnecessary leap between the B and E notes. In number eight of his 13 fingering principles, Whitcomb suggests avoiding such shifts. However, it does enable the third group of quavers to be executed on three separate strings, G, D and A respectively, emphasising the arpeggiated figure. Like Grützmacher's edition, Klengel instructs the cellist to move up the fingerboard using the D string as well the A string in bars 102 and 103. 


\section{LIEFF \& MARIE ROSANOFF}



The first eight quavers of bar 96 are played in one position where the thumb is anchored on the second quaver note and the remaining fingers move around this thumb position pivot point. It is not until the last quaver of beat three, after the $\mathrm{D}$ harmonic, that the hand placement changes back a semitone to accommodate a fourth finger on the $\mathrm{G}$ quaver. The hand then shifts again to the $\mathrm{C}$ sharp with a third finger in first position. In bar 97 the fingering changes on every repeated note in the sequence, giving a total of five shifts in both bars 97 and 98.

The first quaver of bar 100 is given two options of fingering; either an open D string or a stopped first finger on the G string. If the latter is chosen, it is unclear where the cellist would place the remaining notes of the arpeggio. There are no other suggestions published in the edition. Thus it could be assumed that there needs to be a quick shift back to first position with a third finger on the $\mathrm{F}$ sharp, or a continuation up the $G$ and $D$ strings without any printed fingerings.

Climbing up the A string in bar 102, there is no pattern seen in the fingering positions. At first it seems that there is a consistent first finger shift on every beat, however this pattern changes in the last group of quavers where a third finger is used to shift between the beat to the D5 quaver. After the peak is reached in the passage, the arpeggio descent is executed on the D string until an open string is indicated in the third group of quavers for the A quaver note. Instead of remaining in first position, the F sharp quaver of the last beat of bar 103 and the first two notes of bar 104 are briefly placed in third position before going back to first position to finish the Prelude. 

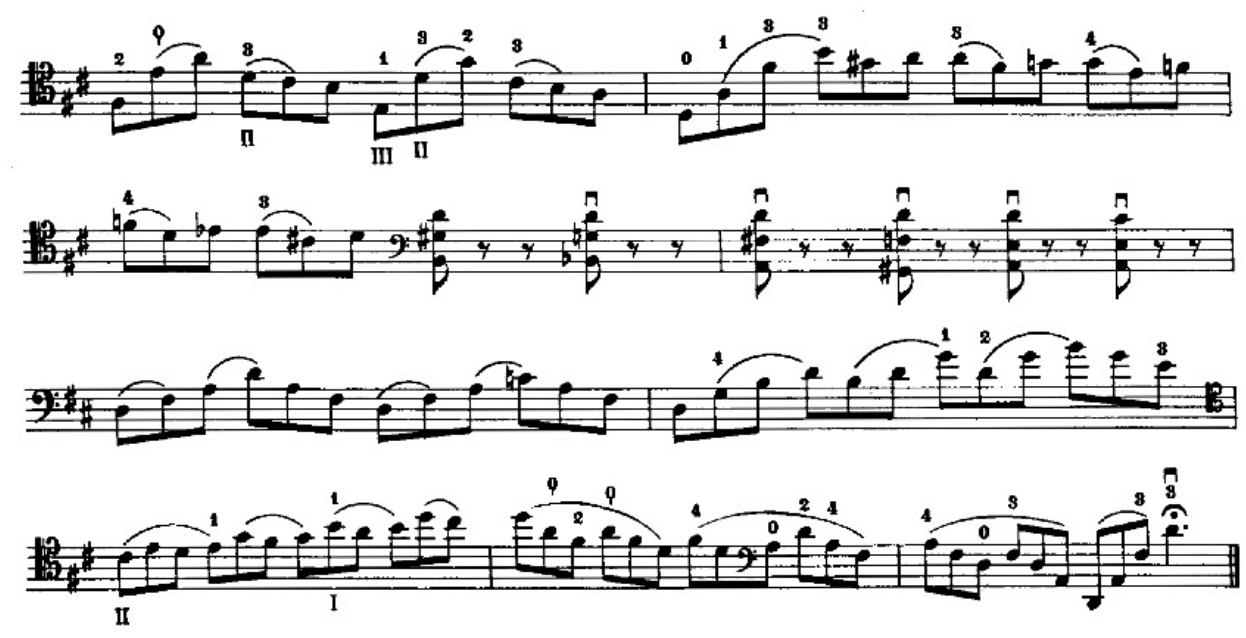

The fingerings that Starker has included in this passage are very similar to the ones found in the Becker edition. From bar 96 through to the first half of bar 103, the suggested fingerings are the same. In some cases, such as in bar 99, there are no fingerings notated, thus it is left to the performer's discretion. The second half of bar 103 until the end has different fingering to Becker's as Starker moves into fourth position with a fourth finger on the F sharp. Another shift in position is seen on the following dotted crotchet beat to a second finger. Unlike Becker, who notates a fourth finger on the D quaver note in bar 103, Starker's edition does not move into first position until bar 104. Both editions however end the last note of the Prelude on the D string.

\section{AUGUST WENZINGER}
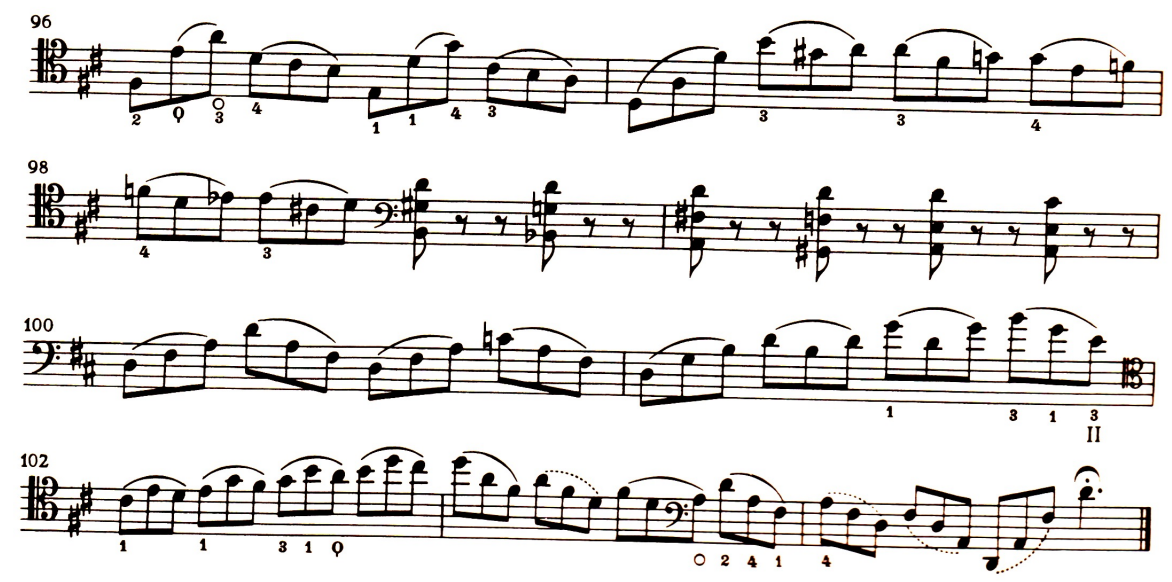

The first three quaver notes of this passage remain in the position already set up from previous bars with the thumb anchored on the E4 note. The last of these notes, A4, is marked with a harmonic sign 'o' allowing the cellist time to get back to first position in order to play the first note of the second beat with a stopped fourth finger. Wenzinger's edition includes fingerings that match the bowing articulations notated. This makes sure that there are no audible shifts between notes. For example, 
instead of slurring all the notes within the first and third beats of bar 96, only the last two quavers are slurred, allowing the cellist to change from first position to third between the notes $\mathrm{E}$ and $\mathrm{D}$ with an imperceptible shift.

In bars 97 and 98, the fingerings notated instruct the performer to shift on each beat of the bar, and together with the change of bows also on the beat, this helps to mask any shifts that may be heard. At the end of bar 101 the $\mathrm{G}$ major arpeggio goes on to the D string with a third finger for the B quaver. This allows the majority of bar 102 to be executed from one position rather than changing fingerings multiple times if it were on the A string. There are no fingering suggestions for the three-note chords. 


\section{PART TWO}

\section{AUTHOR'S NOTES}

The version of the Prelude presented in this exegesis results from a combination of the findings in Part One as well as my own technical facility and pedagogical knowledge acquired over many years of cello tuition. Before approaching this task, I felt it appropriate to establish a few core principles that I could use as general guidelines to help me in my quest for the best fingerings. Firstly referring to the Whitcomb text, I selected the following principles to abide by for the majority of the piece. The selection is not in order of importance:

1. Shift between phrases

2. Shift to strong beats

3. Shift after open strings

4. Select a combination of positions that minimises the number of shifts

I also decided to incorporate two principles of my own that I felt were appropriate:

1. Have consistent fingering suggestions when note patterns are repeated

2. Favour open strings over stopped notes

The Bärenreiter Urtext, ${ }^{26}$ wiped of all editorial markings, provided me the perfected foundation to notate my own performance directions that will be presented in my final recital in January 2014. The Urtext exhibits the various pitch discrepancies that lie between the five sources. In cases where the different pitches are provided, I chose the more common option found between the eleven examined editions of Part One. These bars have been marked with my directions, whilst the other options have been blanked.

The first two bars of the Prelude immediately establish the joyful and majestic character of the movement. They engage the listener by revelling in the D major key, set up from the foundation of the pedal note motif that recurs throughout the piece. I felt it imperative to derive a set of fingerings that would help to emphasise this pedal line from the moving melodic line. I also wanted to remain consistent with the pattern so that each time the two-bar phrase returned, the same fingers would be

${ }^{26}$ Johann Sebastian Bach. 6 Suites a Violoncello Solo senza Basso 'Urtext: Scholarly Critical Performing Edition'. Edited by Bettina Schwemer and Douglas Woodfull-Harris. (Kassel: Bärenreiter, 2000). pp. 54 - 57. 
used. The end result showcases the same fingering pattern found in the Fournier edition with the exception of the last quaver of beat four, where a third finger harmonic to the D4 note is included rather than a fourth. The fingerings presented not only allow my hand to remain in one position, but they ensure that the pedal line and the moving line are for the majority of the phrase separated on different strings.

Another instance where I felt it best to differentiate the pedal note and moving melodic lines is found in bars 23 to 32. Again, following the principle of implementing a consistent fingering pattern was of upmost importance. I therefore reserved the thumb for the E pedal note so it could be used as an anchor or pivot point for the remaining fingers to play the melodic line. I largely followed this convention from the Becker, Grützmacher and Klengel editions. Instead of playing this passage on the G and D strings, as these editors suggested within their publications, I transferred the hand placement to the A and D strings. Although this causes the hand to be extended for the majority of the passage, I felt that being lower on the fingerboard but on the higher strings would make a cleaner and brighter sound, closer emulating the timbre of the missing E open string.

The fingering pattern for the duration of the phrase is consistent. However, it does change at certain times in order to compensate for inconvenient stretches created from the thumb being used solely for the E pedal note on the A string. This requires considerable technical skill from the player as the placements of certain notes become harder to reach. For example, within bar 23, the last quaver of beat three and first quaver of beat four (F sharp and E) require an awkward stretch. Although technically they are only a tone apart, and could both be played on the A string, the guideline for the thumb to exclusively play the pedal line makes this option redundant and therefore the first quaver of beat four needs to be played on the D string. Furthermore, where there is an E quaver note following the E pedal note in the passage, such as in bars 26 and 30, this pattern requires the note before the pedal to be played with a first finger thus allowing the third finger to be free to stretch comfortably for the E quaver note on the D string. This is also the case in bar 29 for the major third stretch between the first and last quavers of beat three.

Overall, this passage was greatly varied with fingering patterns between the editions. The application of principles previously established created a good foundation and starting point when deciding upon the fingerings to use. The Tim Hugh edition is the closest in terms of fingerings that match my final result. Although he notates very few fingerings within this passage, the ones that are printed match the ones included within my version. An exception to this however is found in bars 30 and 31 where Hugh has a third finger shift between the semitone of notes D sharp and E. I instead include a second and third finger to play these notes. 
Following my principle of playing open strings where possible and shifting on the beat helped me greatly when choosing the fingerings for bars 96 through to 104 . The hand predominantly remains in first position from bar 100 onwards and shifts on the beat with a first finger up the fingerboard for the ascending arpeggio figures. In bar 103, instead of coming back down the A string, crossing over to the D string with a thumb anchored on the A and D harmonics minimises the number of shifts and in turn creates an open sound because of the harmonic timbre. On the last quaver of beat three of the same bar, an open A note allows the hand to move back efficiently to first position in order to play a stopped D quaver with the fourth finger.

I do deviate from the rule of shifting on the beat in bars 96 and 97 for a number of reasons. Firstly, in the third group of quavers of bar 96, a shift within the beat is required in order to reach the G3 quaver note. I thus decided the best approach was to shift with a first finger from the E quaver to the D. I could have notated the $D$ with a fourth finger and then shift to the $G$ with the same finger. However, in order to play the $\mathrm{C}$ sharp quaver of the next beat in first position, I would have to shift twice in succession. Shifting consecutively is not an efficient method nor does it allow for a clean sounding phrase, as it is likely for the shift to be audible. Secondly, in bar 97, I again notate a shift to be used within the third beat of the bar. After playing the A4 harmonic quaver with a third finger, the next note F sharp is to be played with the same finger so that the hand is in position to play the next four quavers before resuming to shifting on the beat at the start of bar 98. I felt that this pattern was more comfortable for my hand.

The edition of Part One most closely resembling the fingering patterns that are incorporated in my version is the Tim Hugh score. There are a few exceptions for instance on the last quaver of beat three in bar 96, the editor notates a third finger. He also instructs the performer to play on the D string in bar 102 whereas I prefer to execute this bar on the A string. The last few bars of my version, particularly from bar 103 onwards, follow the suggestions found in the Wenzinger edition as this editor also uses the D string for the arpeggio decent. 


\section{AUTHOR'S VERSION \\ Suite VI}

BWV 1012
Johann Sebastian Bach

Bärenreiter Verlag Urtext Publication

Edited by Alexandra Partridge

Prélude
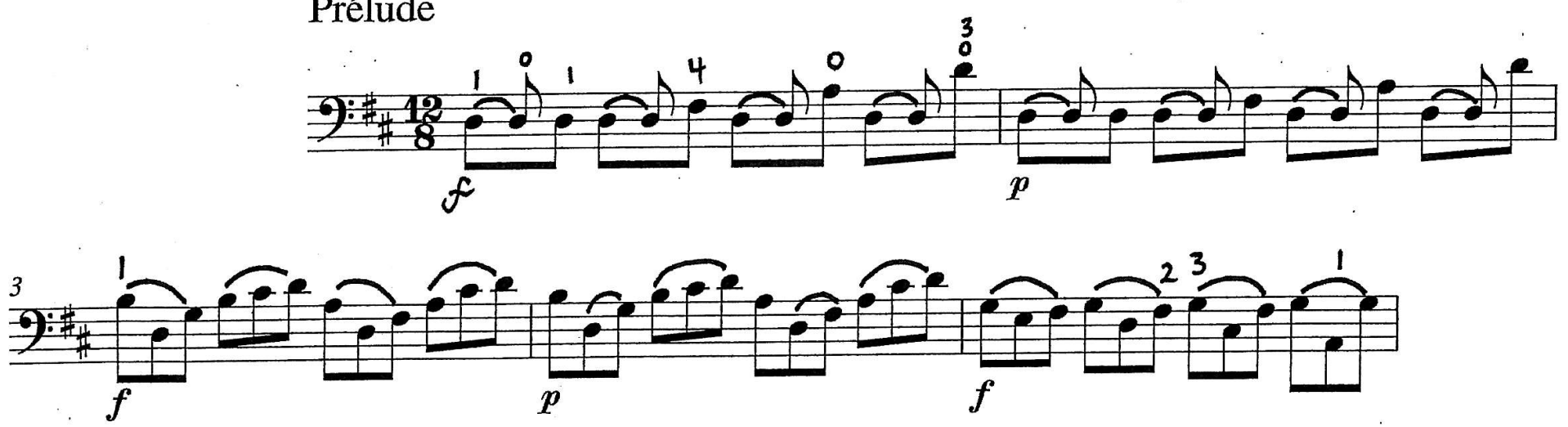

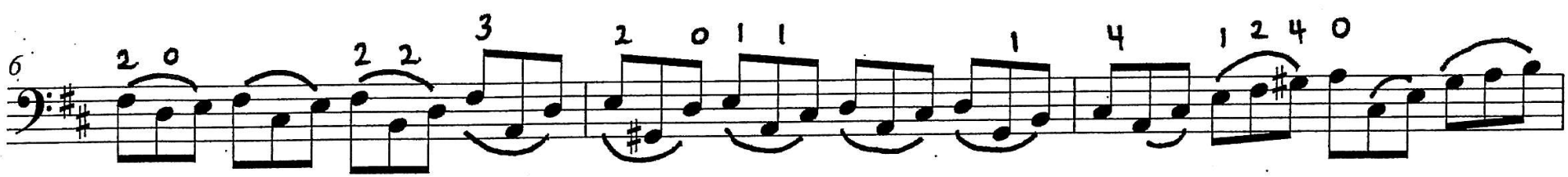

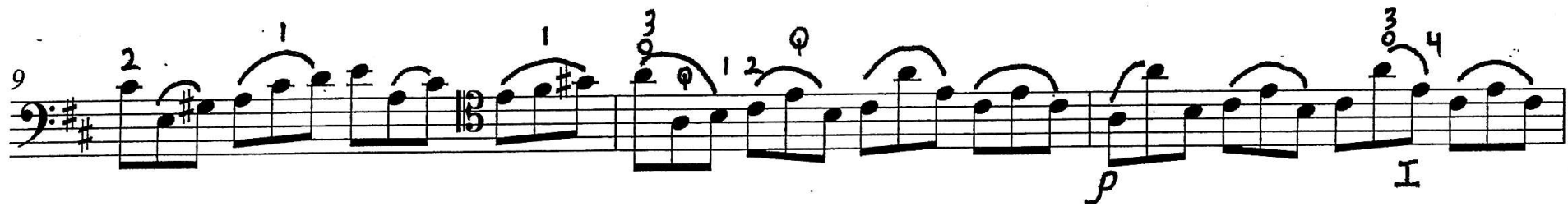
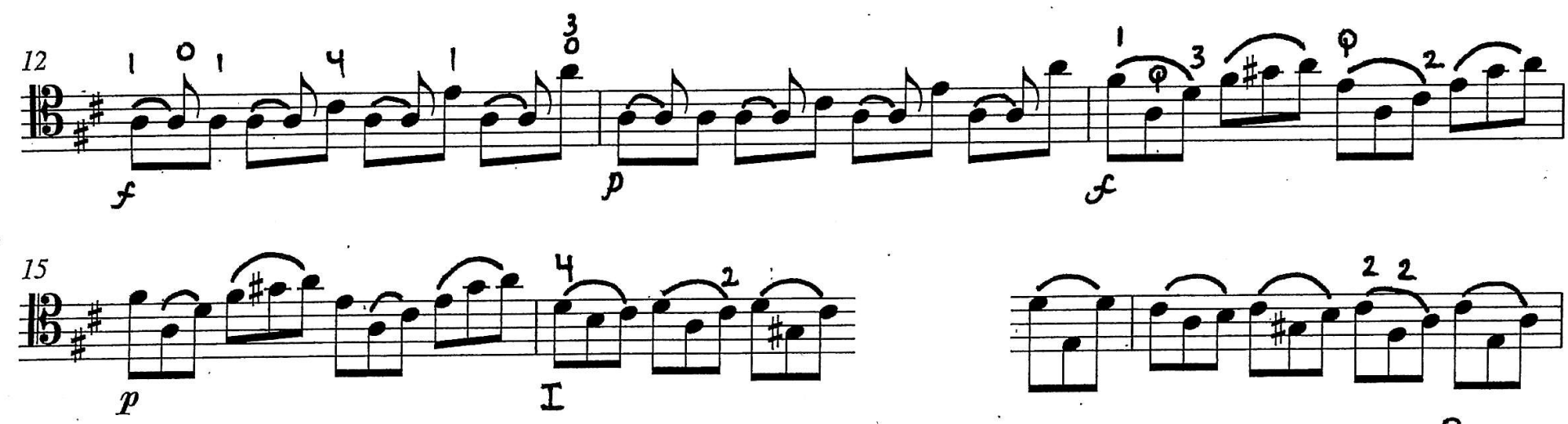

居
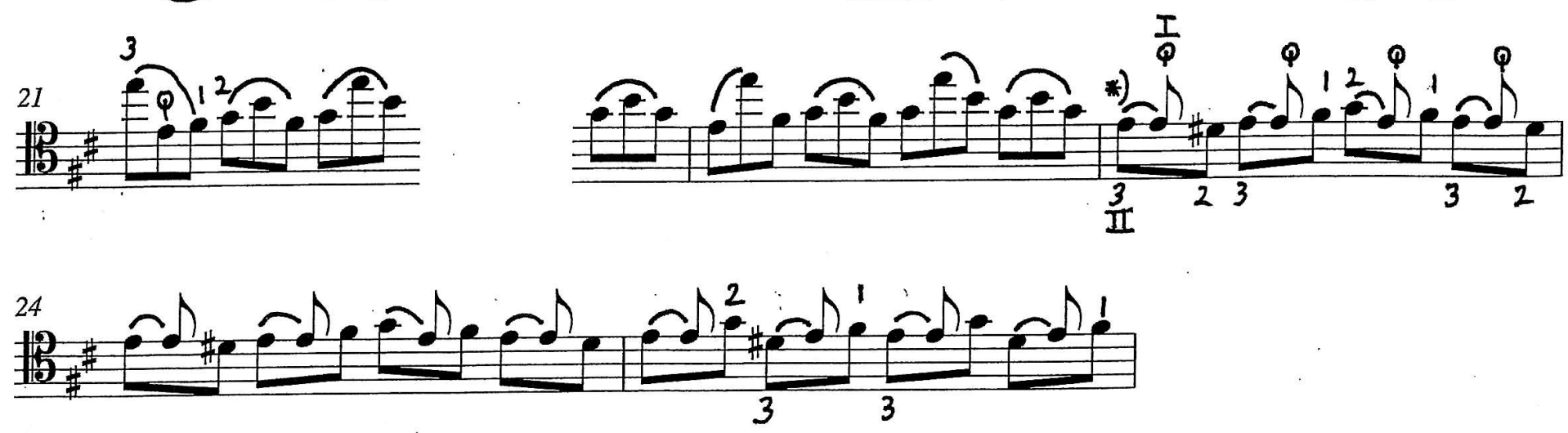

*) fingerings notated above stave are played on the A string and those below stave are played on the D string 


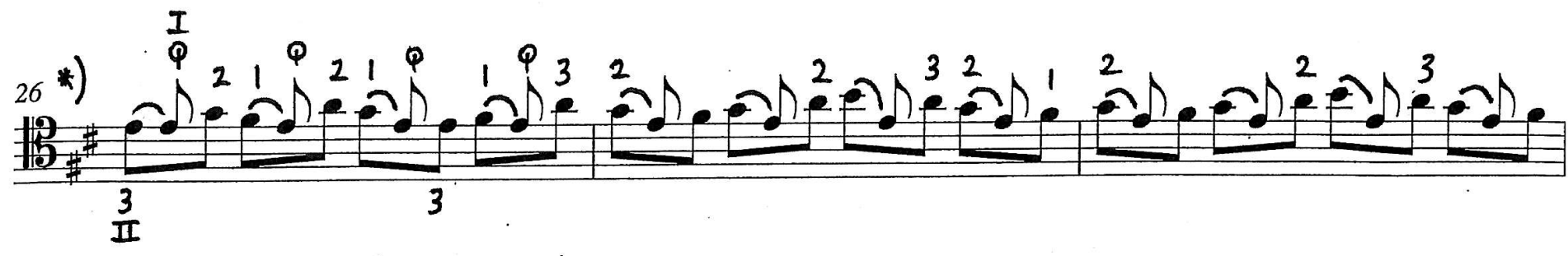

29.20.0.

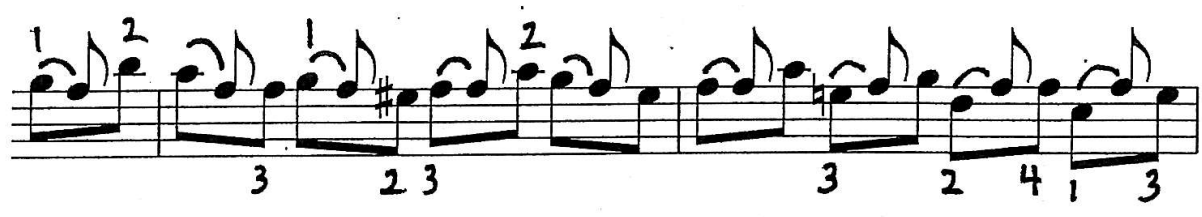

(19)

势

局

9.

\begin{tabular}{l}
122 \\
15.21 \\
\hline
\end{tabular}

II

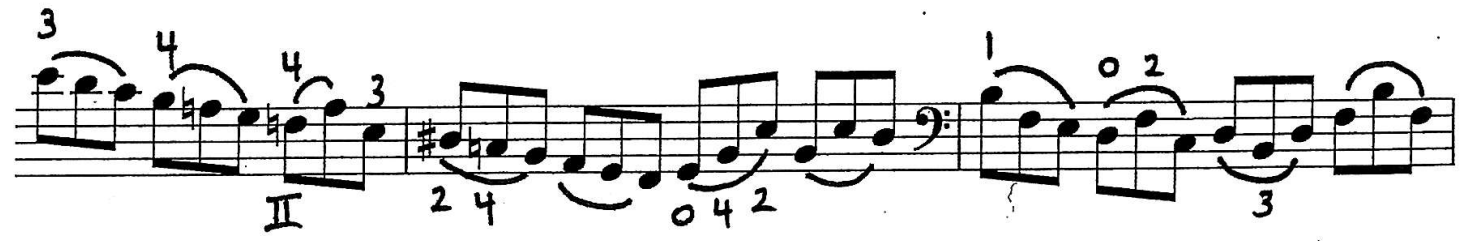

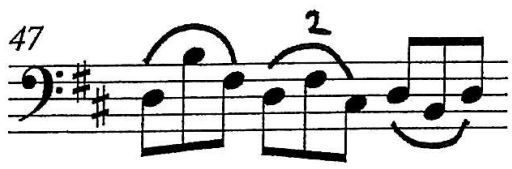

III
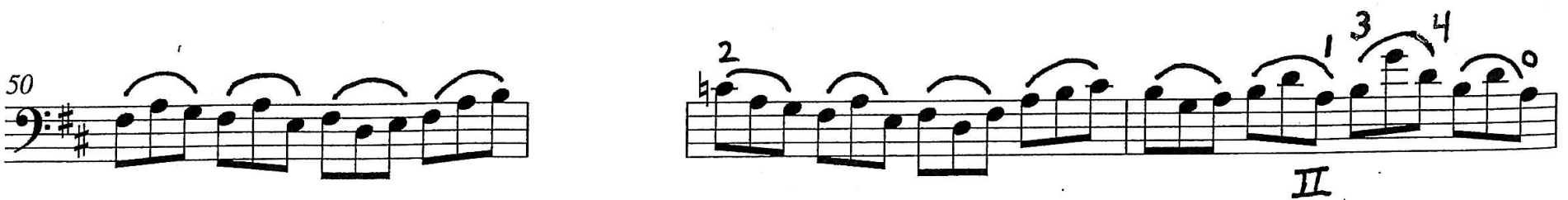


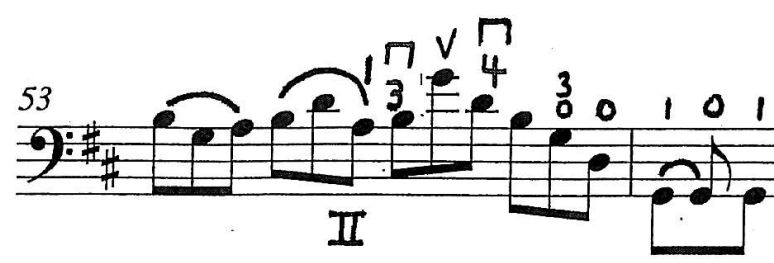

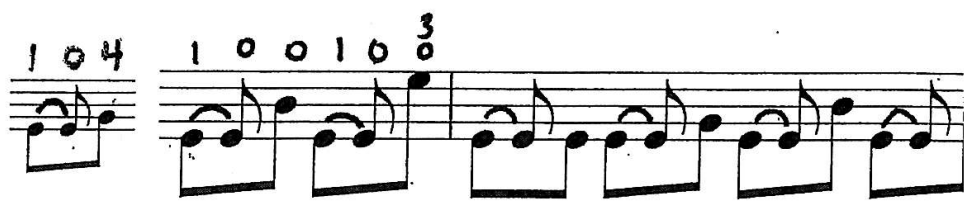

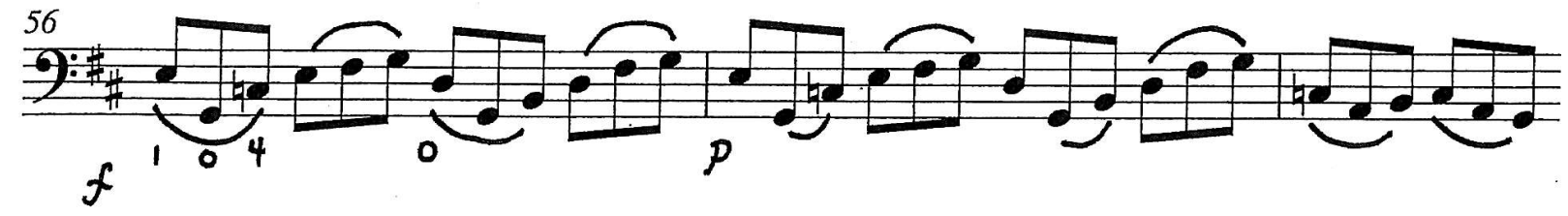
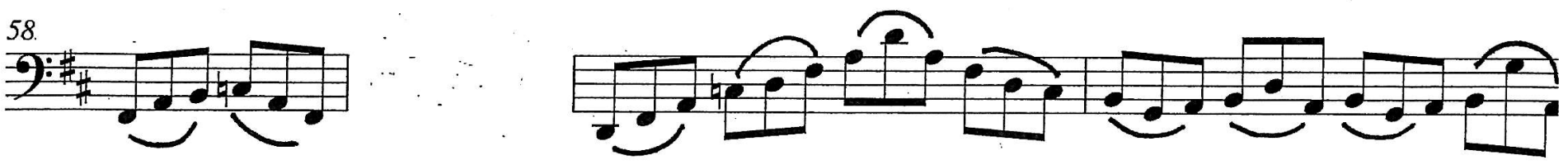

$9:+200$

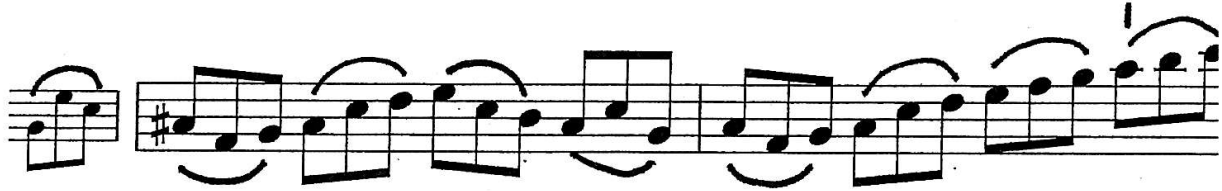

(9)

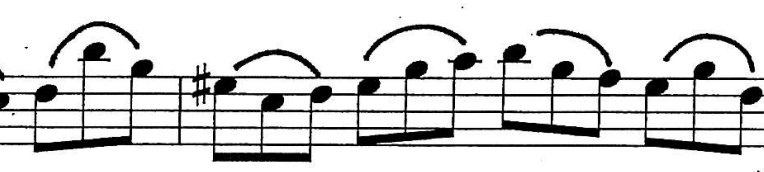

掉

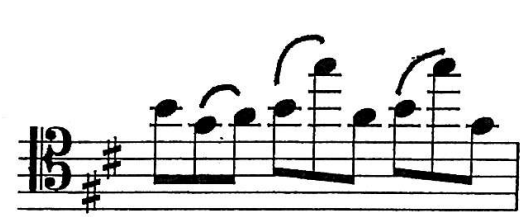

Q 3

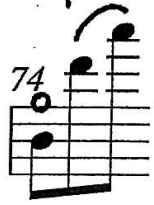

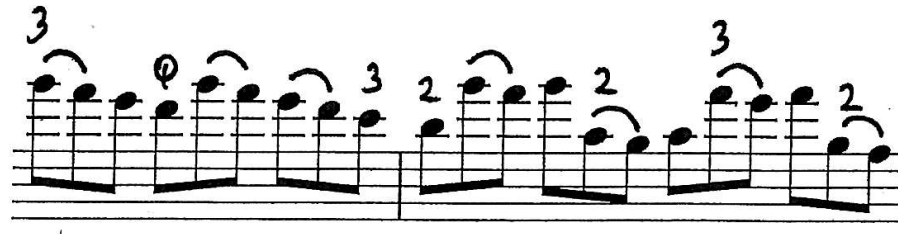

II

123

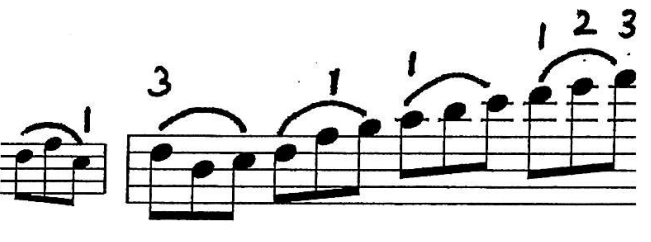

若

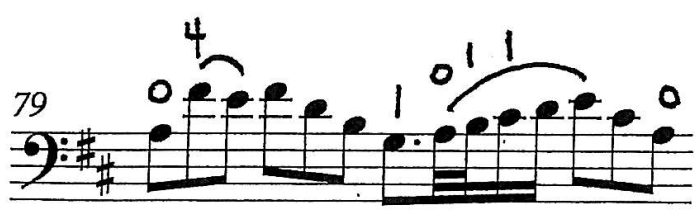

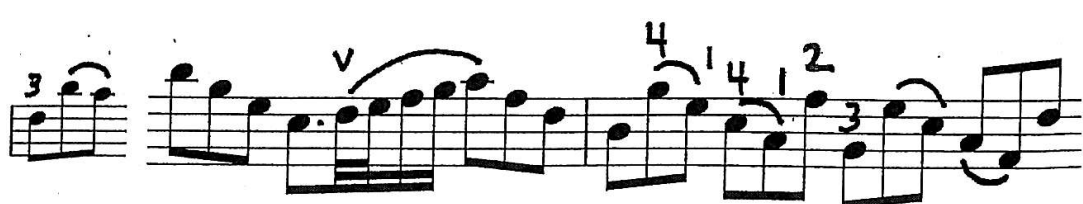




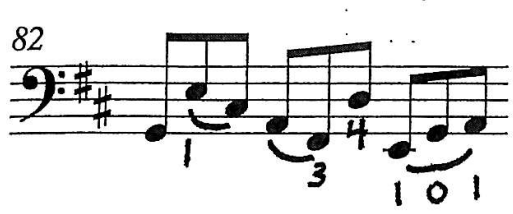


29:4



$I$

9:\#

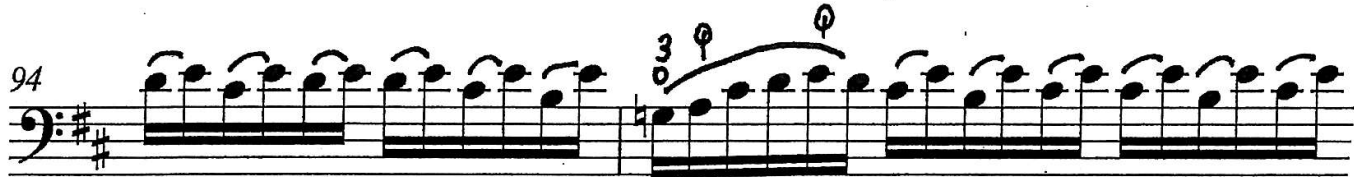

年争

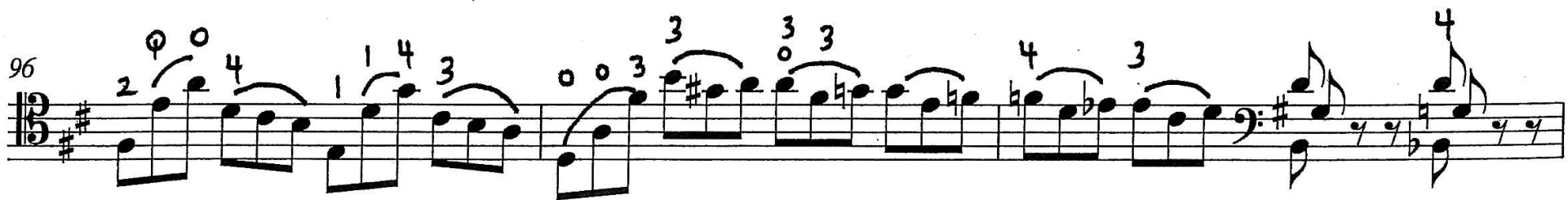

9):

节 


\section{CONCLUSION}

Fingering patterns facilitate a way of playing that appeals to the individual performer. Although it is easy to rely on prior knowledge or to follow what is notated on the score when applying fingerings within performance, it is beneficial to explore other options by examining a range of editions. By seeking alternative suggestions, a wider scope and breadth of choice becomes available to the performer, thus allowing the possibility of informed choices that previously may not have been conceived.

In Part One of this comparative study of J.S. Bach's Prelude from the sixth suite, it is evident that the fingering suggestions incorporated within the eleven publications vary greatly. Where some editors seem to adopt fingering methods that follow technical considerations, as is often found in Starker's edition, du Pré and other editors such as Wenzinger and Rosanoff appear to base their fingering decisions primarily on musical integrity. More often than not, a combination of fingerings that present both musical and technical facility was integrated within the scores; nonetheless each edition is quite different.

In Part Two, the author has proposed a performing version, which was conceived by analysing the various editions and then incorporating those elements that suit her understanding of the music and her technical ability. The end result is independent of the eleven editions; however, the three extracts that were used in the study follow the Tim Hugh edition more closely than the other ten editions.

The process of analysing the notated fingering suggestions within eleven editions helped the author to gain a range of different perspectives. Not only did it provide a range of options to overcome the issue of playing the movement without a fifth string (particularly the extract of bars 23 to 32), but it also gave insight into different ways in which a phrase could be expressed. 


\title{
APPENDIX
}

\section{LEARN TO DEVISE THE BEST FINGERINGS By Benjamin Whitcomb}

\author{
Learn to devise the best cello fingerings
}

IN THE WORLD OF THE CELLO, it's no secret that good playing requires good fingerings. But how can you decide what distinguishes a good fingering from a bad one, and what criteria can you use to figure out the best possible fingering solution? Find the answers by following a simple set of steps.

A discussion of cello fingerings is largely a discussion of when and where to shift (along with which finger to shift to and from, which position to shift to, and on which string). Since there are both technical and musical reasons for shifting, you can further divide the criteria for good fingerings into these two categories as well.

Most situations involve both musical and technical reasons for shifting, but it is useful to keep their different purposes distinct in one's mind.

I have identified the 13 most common and-most important-technical criteria for shifting to the right. These criteria can also be broken down further into fast technique and slow technique.

Fast technique is about such things as precision and accuracy, cleanliness, and articulation, and it usually involves playing closer to the tips of the fingers.

Slow technique, on the other hand, is more about a beautiful tone and vibrato, imitating the portamenti, sustain, and the language of the human voice, and it generally involves playing more on the pads of the fingers.

In most cases, for technical shifts, violating one of the following criteria has a cost in terms of the amount of effort involved, the time it takes, and the degree of accuracy that is likely to result. Once you've determined the best fingering given these criteria, make sure to mark it in your music with a pencil-you wouldn't want to do the work twice!

\section{TECHNICAL CONSIDERATIONS FOR FINGERINGS}

The criteria are not listed in order of importance.

1. Select a combination of positions that minimizes the number of shifts.

2. Select a combination of positions that minimizes the size of the largest shifts.

3. In fast technique, try to shift on the stronger beats whenever possible.

4. Shift at a half-step wherever possible.

5. Avoid awkward string-crossing patterns.

6. Favor stronger fingers over weaker ones.

7. Avoid playing only one note in a given position whenever possible. 
8. Try to avoid using the same finger to play two adjacent notes in different positions on different strings.

9. Shift between phrases whenever possible.

10. Shift to avoid successive perfect fifths.

11. Shift during an open string (or a harmonic) whenever feasible.

12. Select regular positions over extended positions.

13. Minimize the number of times that you change finger spacings.

I have provided examples of fingerings that demonstrate each criterion (see page 33) from

Tchaikovsky's Serenade in C major for Strings, Op. 48, and Mendelssohn's Fourth Symphony. Let's further discuss these criteria in order to better understand them.

In real life you'll almost never choose a particular fingering based on only one criterion. Once you know these criteria, you can spend the rest of your life figuring out how best to prioritize them in any given passage of music.

\section{MUSICAL CONSIDERATIONS FOR FINGERINGS}

In addition to technical considerations for fingerings, there are musical considerations:

1. To purposefully create audible shifts for expressive purposes;

2. To add variety and interest;

3. To fit the sound's color to the musical line;

4. To make the shifts inaudible;

5. To prevent the musical line from suffering or being disturbed.

These musical considerations apply mostly to slow technique. In fast technique, a player tends to shift more often for technical reasons.

The degree to which each musical priority applies is completely dependent on, and can vary considerably with, the musical context and the performer's interpretation and intentions. Musical priorities can and should "trump" the technical criteria at any time.

\section{APPLYING THE CRITERIA}

Before you start writing your own fingerings, you may want to study carefully the fingerings of others. Sure, we have all played other cellists' fingerings, but have you ever considered alternate possibilities and why this cellist thought this particular fingering was the best?

The first step toward accomplishing this is to understand the aforementioned criteria. The next step is to systematically consider all possible fingerings for any given passage. In order to do this, one must consider:

* All possible locations for every shift;

* The possibility of using each of your five fingers before and after the shift;

* Playing the notes on as many of the four strings as possible. 
To ensure that you have considered all possibilities for a passage, take each note in turn and systematically consider the ramifications of trying to play that pitch with each of your five fingers and on as many of the four strings as possible.

You might be saying to yourself that, even for a short excerpt, the number of possibilities would run into the tens of thousands, and you would be correct. But you can quickly rule out any fingerings that would truly have no desirable qualities at all.

\section{MAKE YOUR MARK}

You must learn to mark your fingerings well and clearly. If you come up with a good fingering that you might forget, you should mark it. If you miss a fingering more than once, then mark it, or, if it was already marked, mark it better or more clearly! Also, be sure to specify the string if there could be any doubt at all! Many cellists neglect to do this.

The fingerings you derive by just looking at the music, but not playing it (like solving a puzzle) are sometimes quite different from what you devise while playing. You should use the fingerings you favor while playing the cello. Likewise, the fingerings you devise while playing music from memory are sometimes quite different from those you devise while playing and reading the music. Trust the fingerings you devise when you practice from memory.

Favor the fingerings that make you sound best at that point in your life, but always strive to expand your viable options.

Practice extending between fingers other than first and second, or work on double extensions, or pivots, all while playing various etudes and exercises during your warmup routine. Also work on what I call "quasi-shifts" (half extension, half shift). Increase your finger strength and independence.

There will be times when you have to make up fingerings as you go (such as when you're sight-reading). In these cases, it is very useful to have practiced using some unconventional fingerings.

Keep your mind open to all the possibilities. Get in the habit of weighing the merits of at least two fingering solutions for any given passage. You may be astonished at the brilliant fingerings you end up discovering! 


\section{BIBLIOGRAPHY}

\section{SOURCES}
A. Anna Magdalena Bach, c. 1730.
B. Johann Peter Kellner, 1726.
C. (Anonymous) Johann Christoph Westphal, c. 1750.
D. (Anonymous) Vienna, Late $18^{\text {th }}$ Century.
E. First edition. Louis Norblin. Janet et Cotelle, Paris, 1824.

\section{EDITIONS}

Bach, Johann Sebastian. 6 Sonaten für Violoncell. Edited by Friedrich Dotzauer. Leipzig: Breitkopf \& Härtel, 1826.

Bach, Johann Sebastian. 6 Suites for Violoncello Solo. Edited by Jaqueline du Pré. Copenhagen: Edition Wilhelm Hansen, 1981.

Bach, Johann Sebastian. Bach Cello Suites. Edited by Tim Hugh. Great Britain: Kevin Mayhew Ltd., 2005.

Bach, Johann Sebastian. Bach Six Suites for Violoncello Solo. Edited by Frits Gaillard. Milwaukee: G. Schirmer, 1939.

Bach, Johann Sebastian. Sechs Suiten (Sonaten) für Violoncello Solo. Edited by Hugo Becker. Leipzig: C.F. Peters, 1911.

Bach, Johann Sebastian. Six Solo Suites for Violoncello. Edited by Marie Roemaet Rosanoff and Lieff Rosanoff. Massachusetts: ECS Publishing: Galaxy Music Corporation, 1963.

Bach, Johann Sebastian. Six Suites for Cello Solo. Edited by Pierre Fournier. New York: International Music Company, 1972.

Bach, Johann Sebastian. Six Suites for Solo Cello. Edited by Julius Klengel. Leipzig: Breitkopf \& Härtel, 1900.

Bach, Johann Sebastian. Six Suites for Unaccompanied Violoncello. Edited by Janos Starker. New York: Peer International Corporation, 1971.

Bach, Johann Sebastian. Six Suites for Violoncello Solo BWV 1007-1012. Edited by August Wenzinger. Basel: Bärenreiter-Verlag, 1950.

Bach, Johann Sebastian. Sechs Suiten (Sonaten) für Violoncello Solo. Edited by Friedrich Grützmacher. Leipzig: C.F. Peters, 1865. 


\section{REFERENCES}

Bach, Johann Sebastian. 6 Suites a Violoncello Solo senza Basso BWV 1007-1012 'Urtext: Scholarly Critical Performing Edition'. Edited by Bettina Schwemer and Douglas Woodfull-Harris. Germany: Bärenreiter Kassel, 2000.d

Badiarov, Dimtry. "The Violoncello, Viola da Spalla and Viola Pomposa in Theory and Practice." The Galpin Society Journal (Galpin Society) 60 (April 2007): 121-145.

Davis, Nathan J. The Baroque Violoncello and the Unaccompanied Cello Suites of J.S Bach BWV 1007-1012. New York: University Microfilms International, 1989.

Eisenberg, Maurice. Cello Playing of Today. London: The Strad, 1957.

Eppstein, Hans. Johann Sebastian Bach Neue Ausgabe sämtlicher Werke, Series VI, Band 2. Kassel: Bärenreiter, Kritische Bericht, 1990.

Janof, Tim. A Survey of Bach Suite Editions. 1995.

http://www.cello.org/Newsletter/Articles/jsbach.html.

Kinney, Gordon James. Musical Literature for Unaccompanied Violoncello. Ph.D. diss., Florida State University, 1962.

Kite-Powell, Jeffery. A Performer's Guide to Seventeenth-Century Music. Second. Edited by Stewart Carter. Indiana: Indiana University Press, 2012.

Maurice, Donald. "The Art of Vocal Fingerings in String Playing." American String Teacher 56, no. 3 (August 2006): 27-31.

Prindle, Daniel E. The Form of the Prelude to Bach's Unaccompanied Cello Suites. University of Massachusetts, 2011.

Schwemer, Bettina, and Douglas Woodfull-Harris. 6 Suites a Violoncello Solo senza Basso BWV 10071012 'Text Volume'. Germany: Bärenreiter Kassel, 2000.

Starker, János. An Organized Method of String Playing . USA: Peer International Corporation, 1965.

Thomas, Rhiannon. Johann Sebastian Bach's Unaccompanied Cello Suites (BWV 1007 - 1012) Sources, Editions and Interpretations. Wellington: Victoria University, 1996.

Whitcomb, Benjamin. Strings 101: Music \& Musicians - World of Possibilities: Learn to Devise the Best Cello Fingerings. March 2008.

http://search.proquest.com.helicon.vuw.ac.nz/docview/1409812?accountid=14782 (accessed August 30, 2013).

Williams, Peter. J.S Bach: A Life in Music. Cambridge: Cambridge University Press, 2007. 


\section{OTHER MATERIAL NOT REFERENCED}

Battie, Robert. Bach Suites and You. 16 January 2013.

http://www.cello.org/Newsletter/Articles/bachsuitesandyou.htm, (accessed March 2013).

Bowen, José. Rethinking Music. Edited by Nicholas Cook and Mark Everist. New York: Oxford University Press, 1999.

Brumbleloe, Joseph. "Patterns and Performances in Selected Perpetual Motion Movements by J.S Bach." Theory and Practice (Music Theory Society of New York State) 25 (2000): 1-25.

Butt, John. The Cambridge Companion to Bach. Cambridge: Cambridge University Press, 1997.

Drabkin, William. Early Music: Fingering in Haydn's String Quartets . Oxford University Press, 1988.

Forkel, Johann Nikolaus. Johann Sebastian Bach: His Life, Art and Work. New York: Harcourt, Brace and Howe, 1920.

Freiberg, Sarah. Reflections on the New Barenreiter Bach. 2000.

http://www.cello.org/newsletter/reviews/bach_frei.htm (accessed March 2013).

Guin, Elizabeth Le. Boccherini's Body: An Essay in Carnal Musicology. University of California Press, 2005.

Janof, Tim. A Survey of Bach Suite Editions. 1995.

http://www.cello.org/Newsletter/Articles/jsbach.html.

Ledbetter, David. Unaccompanied Bach: Performing the Solo Works. New Haven \& London: Yale University Press, 2009.

Lee, Joong-Oh. A Comparison of Selected Editions of Johann Sebastian Bach's Unaccompanied Cello Suite Number Six in D Major BWV 1012 Transciped for Viola. Ph.D. diss., University of Miami, 2004.

Marinescu, Ovidiu. J.S Bach 'A Complete Recording by Ovdiu Marinescu' Program Notes. 2010. http://www.kickstarter.com/projects/marinescu/j-s-bach-six-suites-for-cello-solo-acomplete/posts/30528.

Markevitch, Dimitry. Some Thoughts On More Rational Cello Fingerings. 1999.

http://www.cello.org/Newsletter/Articles/fingers/fingers.htm (accessed July 2013).

Markevitch, Dimitry. The Recent Editions of the Bach Cello Suites. 4 July 2000.

http://www.cello.org/newsletter/articles/bach_mark.htm, (accessed June 2013).

Sayegh, Samir I. "Fingering for String Instruments with the Optimum Path Paradigm." Computer Music Journal (The MIT Press) 13, no. 3 (1989): 76-84.

Tarling, Judy. Baroque String Playing for Ingenious Learners. Corda Music, 2000. 